\title{
A two-dimensional model of the passive coastal margin deep sedimentary carbon and methane cycles
}

\author{
D. E. Archer ${ }^{1}$, B. A. Buffett ${ }^{2}$, and P. C. McGuire ${ }^{1}$ \\ ${ }^{1}$ Department of the Geophysical Sciences, University of Chicago, USA \\ ${ }^{2}$ Department of Earth and Planetary Sciences, University of California, Berkeley, USA
}

Correspondence to: D. E. Archer (d-archer@uchicago.edu)

Received: 28 February 2012 - Published in Biogeosciences Discuss.: 14 March 2012

Revised: 18 June 2012 - Accepted: 19 June 2012 - Published: 1 August 2012

\begin{abstract}
We present a new geologic-time and basin-spatial scale model of the continental margin methane cycle. The model, SpongeBOB, is used to simulate evolution of the carbon cycle in a passive sedimentary continental margin in response to changing oceanographic and geologic forcing over a time scale of 200 million years. The geochemistry of the sediment column is altered by the addition of vertical highpermeability channels intended to mimic the effects of heterogeneity in the real sediment column due to faults, and produces results consistent with measured pore-water tracers $\mathrm{SO}_{4}^{2-}$ and ${ }^{129} \mathrm{I}$. Pore water dissolved inorganic carbon (DIC) concentrations are consistent with chemical weathering $\left(\mathrm{CaCO}_{3}\right.$ formation from igneous rocks) at depth within the sediment column. The carbon isotopic composition of the DIC is consistent with a methane production efficiency from particulate organic carbon (POC) of $50 \%$, which is somewhat lower than redox balance with the $\mathrm{H} / \mathrm{C}$ of organic matter in the model. The hydrate inventory in the model is somewhat less sensitive to temperature than our previous results with a one-dimensional model, quite sensitive to reasonable changes in POC, and extremely sensitive to the ability of methane bubbles to rise within the sediment column, and how far gas-phase methane can get through the sediment column before it redissolves when it reaches undersaturated conditions. Hydrate formation is also sensitive to deep respiration of migrating petroleum. Other phenomena which we simulated had only a small impact on the hydrate inventory, including thermogenic methane production and production/decomposition of dissolved organic carbon.
\end{abstract}

\section{Introduction}

Models of methane hydrate formation in sediments of the deep-sea have tended to follow the example of early diagenesis modeling in adopting a one-dimensional formulation (Burdige, 2011; Chatterjee et al., 2011; Davie and Buffett, 2001, 2003a, b; Garg et al., 2008; He et al., 2011; Liu and Flemings, 2007; Xu, 2004). For the top meter of the sediment column (Archer et al., 2002), the 1-D approximation is a good one because vertical diffusion is far faster than any possible lateral pore fluid transport or diffusional effects. The methane cycle challenges a 1-D formulation, however, because the relevant chemical processes occur hundreds of meters below the sea floor, and clearly show the impact of pore fluid and gas phase migration in more than one dimension. One-dimensional models of the upper sediment require fluid flow imposed as a bottom boundary condition, and the hydrate inventory of the model is very sensitive to this parameter (Buffett and Archer, 2004). The methane cycle is also impacted by time-dependence of the sediment and organic carbon deposition rates, which are governed by onshoreoffshore processes, another benefit of incorporating the second dimension into the model formulation.

SpongeBOB is formulated in the onshore-offshore dimension laterally, and to bedrock in the vertical to internalize the entire coastal margin carbon and methane cycles, of which the methane hydrates near the sea floor are just one manifestation. Many of the processes and mechanisms, such as all the different means of downslope sediment transport or pathways for subsurface fluid flow, are impossible to represent accurately given our present state of knowledge; however, by representing them as best we are able, we hope to gain some 


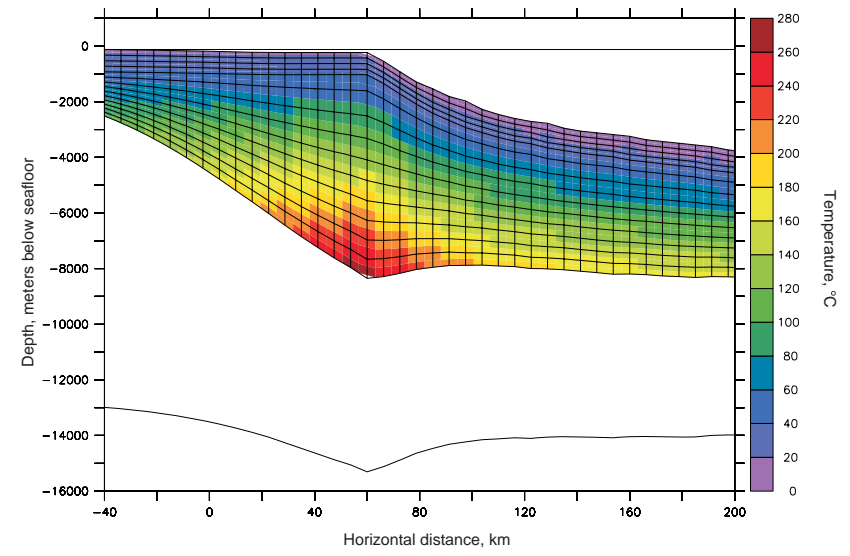

Fig. 1. SpongeBOB in isostatic equilibrium. Colors are temperatures on the computational grid of the model, traced horizontally by the black lines. The thickness of the underlying crust grades from thin ocean crust on the right side of the domain into a thicker (and less dense) continental crust on the left. The transition between ocean and continental crust is smoothed over a spatial scale of $25 \mathrm{~km}$. Local isostasy applies, on a time scale of $10000 \mathrm{yr}$ and with spatial smoothing over $20 \mathrm{~km}$. An animation of the simulation is archived in the Supplement and can be viewed at http://geosci. uchicago.edu/ $\sim$ archer/spongebob_passive/fig1.atlantic.movie.gif.

qualitative picture of the relative importances of the various driving factors and processes.

The model is set up to simulate an accumulating passive continental margin, such as the east coast of the United States, which has been accumulating sediment since rifting of the Atlantic about 200 million yr ago. One of the beststudied locations for methane hydrates is the Blake Ridge, a "drift deposit" ridge jutting out into the Atlantic (Borowski, 2004). The Blake Ridge owes its existence to the hydrodynamics of particle sedimentation, presumably driven by existing topography and the energetic western boundary flow of the Atlantic. Although Blake Ridge is attached to the continental slope of the US, our model results (which only represent the slope, with no drift-deposit ridge) suggest that Blake Ridge might not be entirely typical of slope sediments in general, and thus might be deceptive basis for global extrapolation.

We gauge the sensitivities of this complex model by showing a variety of sensitivity model runs, varying critical parameters or turning processes on and off. The characteristics of the runs will be described as they come up in the model formulation section, and they are summarized in Tables 1 and 2.

\section{Model formulation}

\subsection{Computational grid}

SpongeBOB is formulated on a free-form grid sigma-type vertical coordinate system in depth (Fig. 1), in which the grid cells expand to fill the sediment column as it expands through time, stretching from bedrock to the sediment surface. As sediment accumulates at the sea surface each time step, sediment is also moved between subsurface grid cells in order to maintain the stretched grid. At the beginning of the simulation, all grid cells contain enough solid material to fill a thickness of $1 \mathrm{~m}$. The initial porosity of the cells is "drained", such that the sediment load is carried entirely by the solid matrix with no excess pore fluid pressure to drive a Darcy flow. Sediment is deposited on the top face of the top cell, and a material flow rate is calculated for the bottom face of the top cell, such that the top cell keeps some of the new material for itself but passes most of it on fill the subsurface cells below. The process continues through the sediment column, and the boxes all expand uniformly.

A few grid cells in the top of the domain are restricted, such that they cannot expand beyond a thickness of $200 \mathrm{~m}$, in order to maintain a minimum computational resolution in the region of the hydrate stability zone. After enough model time has passed that a restricted cell reaches its maximum thickness, it passes along the entire incoming advective flux from above into the cell below.

\subsection{Isostasy}

The sediment column elevation is governed by isostasy, the idea that the crust and all the material sitting on top of it are all floating in a denser fluid of mantle material (Watts, 2001). Laterally, the model domain spans between continental crust and ocean crust, as can be seen in the transition in the thickness of the crust in Fig. 1.

The effect of cooling with age on the elevation of the ocean crust is driven by the evolution of a time-dependent thermal boundary layer, extending through the crust into the mantle below. As the material in the crust and the mantle boundary layer cool, they contract and become denser. The thickness of the boundary layer is assumed to increase according to $\Delta z_{\text {boundary }}=\sqrt{\kappa T}$ (Parson and Sclater, 1977) where $\kappa$ is a thermal diffusivity. The temperature profile with depth is assumed to be linear allowing us find the temperature at the crust/mantle boundary by interpolation, from which to compute the average temperatures of the crust and the mantle boundary layer. The temperature at the base of the mantle boundary layer is taken to be $1600 \mathrm{~K}$ (Iamori et al., 1995). The floating pile in the ocean crust end-member consists of the sediment column, the ocean crust, and the thermal boundary layer as it thickens and thermally contracts through time.

The continental crust is simpler because there is no timedependent cooling. The crust is defined to be $13 \mathrm{~km}$ thick and 
Table 1. Model scenarios with uniform sea level and POC deposition state (ocean oxic state $=3$ ).

\begin{tabular}{lll}
\hline Atl, Pac, Anoxic "Atlantic" (ocean state 1) "Pacific" (state 2), and & $\begin{array}{l}\text { Stronger POC dependence for this range of condi- } \\
\text { "Anoxic" (state 4) POC rain forcings, shown in } \\
\text { tions than } T \text { dependence }\end{array}$ \\
& $\begin{array}{ll}\text { Fig. 3. Default is state } 3 \text { ("OMZ") in the } T * \text { runs. } \\
T 0\end{array}$ & $\begin{array}{l}\text { Higher hydrate than the Base case because of higher } \\
\text { POC rain in the last years of the simulation }\end{array}$ \\
$T 2, T 4$ etc. & $2,4,6,8$, and $10^{\circ} \mathrm{C}$ temperature increases & $\begin{array}{l}\text { Weaker temperature sensitivity than the 1-D models } \\
\text { (Fig. 17) }\end{array}$ \\
\end{tabular}

Table 2. Simulations with a time-varying sea level and ocean oxic state (POC deposition).

\begin{tabular}{|c|c|c|}
\hline Simulation name & Characteristics & Salient results \\
\hline Base & Base case at 40 grid cells horizontal resolution & \\
\hline No_Channels Hires & $\begin{array}{l}\text { Horizontal resolution of the Base case but with- } \\
\text { out vertical permeable channels }\end{array}$ & $\begin{array}{l}\text { Somewhat higher overall hydrate inven- } \\
\text { tory }\end{array}$ \\
\hline Base Lores & $\begin{array}{l}\text { Lower resolution version of the full base case } \\
\text { for comparison with sensitivity runs }\end{array}$ & $\begin{array}{l}\text { Somewhat less hydrate than the higher } \\
\text { resolution case }\end{array}$ \\
\hline No Channels Lores & Vertical permeable channels eliminated & Similar hydrate inventory to Lores Base \\
\hline Bubb Mig $100 \mathrm{~m}$,Bubb Mig 2 km & $\begin{array}{l}\text { Redissolution height scale for rising bubbles } \\
\text { from } 500 \mathrm{~m} \text { in base to } 100 \mathrm{~m} \text { and } 2 \mathrm{~km}\end{array}$ & Strong impact on hydrate inventory \\
\hline No Bubb Mig & Bubble migration disabled & Nearly eliminates hydrate \\
\hline Labile $10 \%, \quad$ Labile $100 \%$ & $\begin{array}{l}\text { Changed the biologically-available POC frac- } \\
\text { tion from } 50 \% \text { in base to } 10 \% \text { and } 100 \%\end{array}$ & $\begin{array}{l}\text { Nearly linear dependence of hydrate in- } \\
\text { ventory on rate constant. }\end{array}$ \\
\hline Geotherm 50, 90, 120 & $\begin{array}{l}\text { Geothermal heat flux in } \mathrm{m} \mathrm{W} \mathrm{m}^{-2} \text { relative to } \\
\text { base of } 70\end{array}$ & No hydrate above 90 \\
\hline Low Slope & $\begin{array}{l}\text { The maximum sea floor slope is taken to be } 3 \% \\
\text { instead of } 6 \% \text { in base }\end{array}$ & $\begin{array}{l}\text { Increased hydrate inventory, although } \\
\text { this may not be a robust result based on } \\
\text { prior simulations. }\end{array}$ \\
\hline No Anisotrophy & $\begin{array}{l}\text { Horizontal anisotrophy and vertical permeable } \\
\text { channels eliminated }\end{array}$ & No strong hydrate inventory impact \\
\hline No Clay Dewatering & Clay dewatering reaction eliminated & No strong hydrate inventory impact \\
\hline No DOC & $\begin{array}{l}\text { Dissolved organic carbon production by ther- } \\
\text { mal degradation and sloppy feeding eliminated }\end{array}$ & Small decrease in hydrate inventory \\
\hline No Petroleum & Petrogenesis disabled & Decreases hydrate inventory by $\sim 40 \%$ \\
\hline No Slides & Landslides disabled & No strong hydrate inventory impact \\
\hline No SO4 & $\begin{array}{l}\text { Sulfate, } \mathrm{SO}_{4}^{2-} \text {, held at } 0 \text { concentration in the } \\
\text { ocean }\end{array}$ & $\begin{array}{l}\text { Substantial increase in hydrate inven- } \\
\text { tory }\end{array}$ \\
\hline No Thermogen & Thermal methanogenesis disabled & Decreases hydrates by about $50 \%$ \\
\hline
\end{tabular}

its density is $3.0 \mathrm{~g} \mathrm{~cm}^{-3}$. Any sediment load also contributes to the mass of the column, and the equilibrium elevation of the bedrock.

The blending of domains is done by calculating pure endmember continental and ocean crust scenarios at each model grid point, and then scaling between them using an ad-hoc ocean fraction variable, ranging from 0 for continent to 1 for the ocean end member. The transition is set up with a horizontal length scale of $50 \mathrm{~km}$. For each end member, continental and oceanic, the masses and heights of the column are computed. The two scenarios are blended together at this stage, taking a composite column mass that scales between the two end members, and a composite column height. Although this is not a mechanistic simulation of crustal dynamics at a passive margin, it is sufficient to produce a final envelope of sediment that resembles seismic sections of passive margins (Fig. 4), as a driver for the sedimentary core of the model. 
Sea level is defined as $4000 \mathrm{~m}$ elevation above generic ocean crust. The hypothetical elevation of the top of the mantle, the sea in which the crustal material floats, is defined to be consistent with this.

The equilibrium heights for the top of bedrock are smoothed horizontally through the grid using a diffusion algorithm that achieves a spatial scale of a few tens of kilometers (three passes with a diffusion coefficient of $10^{6} \mathrm{~m}^{2} \mathrm{yr}^{-1}$ ). Flexure and rigidity of the plates becomes important in accretionary margins, but for this study the lateral interaction in isostasy is rudimentary, merely setting the stage for the sediment column. The elevation of the bedrock evolves toward the isostatic equilibrium value with a time constant of $10^{-4} \mathrm{yr}^{-1}$.

\subsection{Sediment dynamics}

\subsubsection{Deposition}

The goals of the sedimentation scheme are to create appropriate sedimentation rates and grain sizes, in adaptive response to a time-evolving submarine landscape. The existence of a shelf break, and the prograding clinoform pattern of sediment deposition, require the existence of a region of fast sediment accumulation just off the shelf break, a sediment depocenter (Pirmez et al., 1998). Sediment input from the continent is also sorted by grain size, with largest grains depositing closer to shore and finer grain sediments offshore (Fig. 2).

Offshore sediment transport and deposition in SpongeBOB is parameterized in an approach following Pirmez et al. (1998). Sediment comes into the model domain on the continental (left-hand) boundary, suspended in the ocean. It advects offshore with a sediment transport velocity, $u_{\text {ocean }}$, that decreases inversely with water depth, as if the ocean margin were a giant river carrying suspended particles away from the continent in a plug flow. Suspended particles settle out following Stokes' law according to their grain size

$W_{\text {sink }}=\frac{\rho_{\text {sediment }} R_{\text {particle }} g}{25 \times 10^{-6} \rho_{\text {seawater }}}$

where $R_{\text {Particle }}$ is the particle radius, $\rho$ stands for density, and $\mathrm{g}$ is Earth's gravitation acceleration. Particles deposit only if the shear stress at the bed, calculated as

$\tau_{\text {shear }}=5 \times 10^{-5} \rho_{\text {seawater }} u_{\text {ocean }}^{2}$,

is too low to lift the particles faster than they sink, determined as a critical shear cutoff

$\tau_{\text {critical }}=\rho_{\text {seawater }} \times w_{\text {sink }}$.

The sediment transport scheme is not mechanistically realistic, but is intended to serve as a realistic boundary condition driver for the sediment column core of the model. The sediment transport offshore velocity $\left(0.1 \mathrm{~m} \mathrm{~s}^{-1}\right.$ in water depth depth of $10 \mathrm{~m}$ ) and the resulting shear deposition scheme
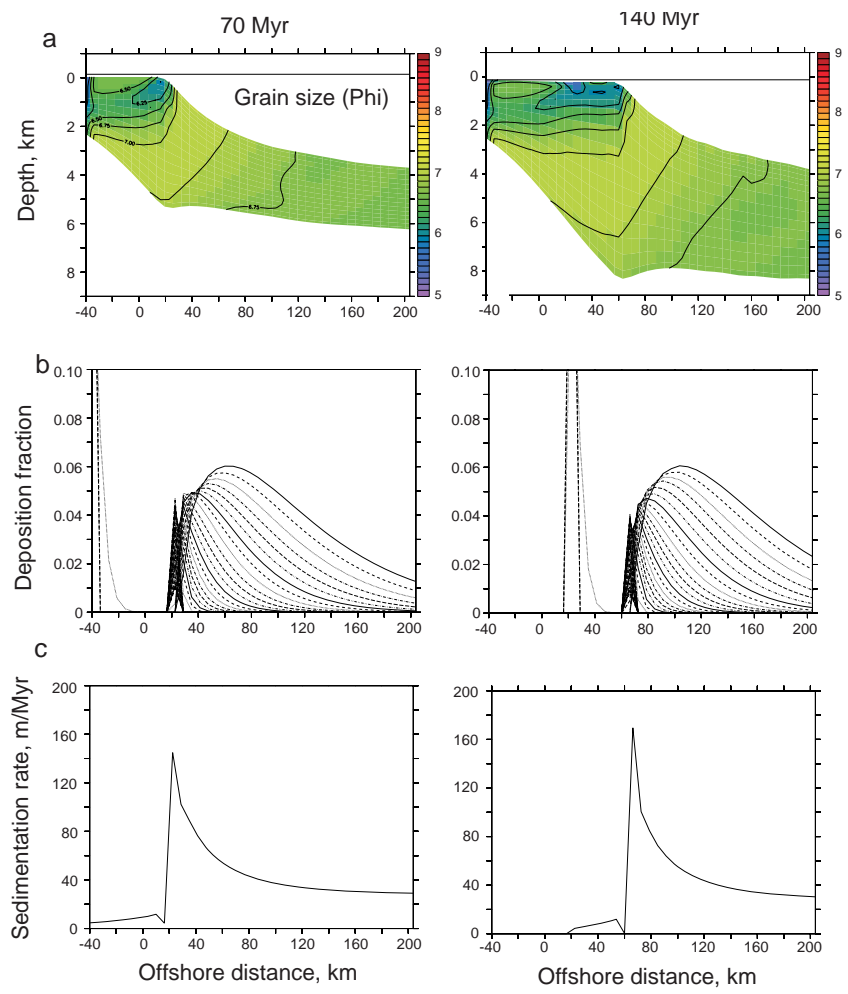

Fig. 2. Sediment transport model results. (A) Mean grain size $\left(\phi=\log _{10}(\mathrm{~mm})\right)$ in the sediment column half-way through (left) and at the end of the simulation (right). (B) Snapshots of the sedimentation rate of particles of various sizes. (C) Snapshots of the total sedimentation rate, with a depocenter just off the shelf break. An animation of this figure is archived in the Supplement and can be viewed at http://geosci.uchicago.edu/ archer/spongebob passive/fig2.atlantic.movie.gif.

were tuned to produce a reasonable facsimile of a seismic section of the Atlantic margin (Fig. 3).

The critical shear velocity depends on particle radius, as does the settling speed, effectively sorting the particles by size with offshore distance. The impact of water depth on the plug flow and hence the shear velocity allows changes in sea level to impact sedimentation and the evolution of the sediment column.

\subsubsection{Slope-driven offshore transport}

Turbidites in abyssal sediments attest to the importance of slope failure to the margin sediment dynamics (Meiburg and Kneller, 2010). These processes are handled as a function of the sea floor grade. If the grade exceeds a critical value, here taken to be $6 \%$, the material that would deposit according to the shear/sinking speed criterion is instead classified as "resuspended". Also, if the sea floor slope ever manages to exceed the critical slope, surface sediment is eroded into the resuspended pool. The resuspended material redeposits using the same settling speed/offshore transport criterion as 
a

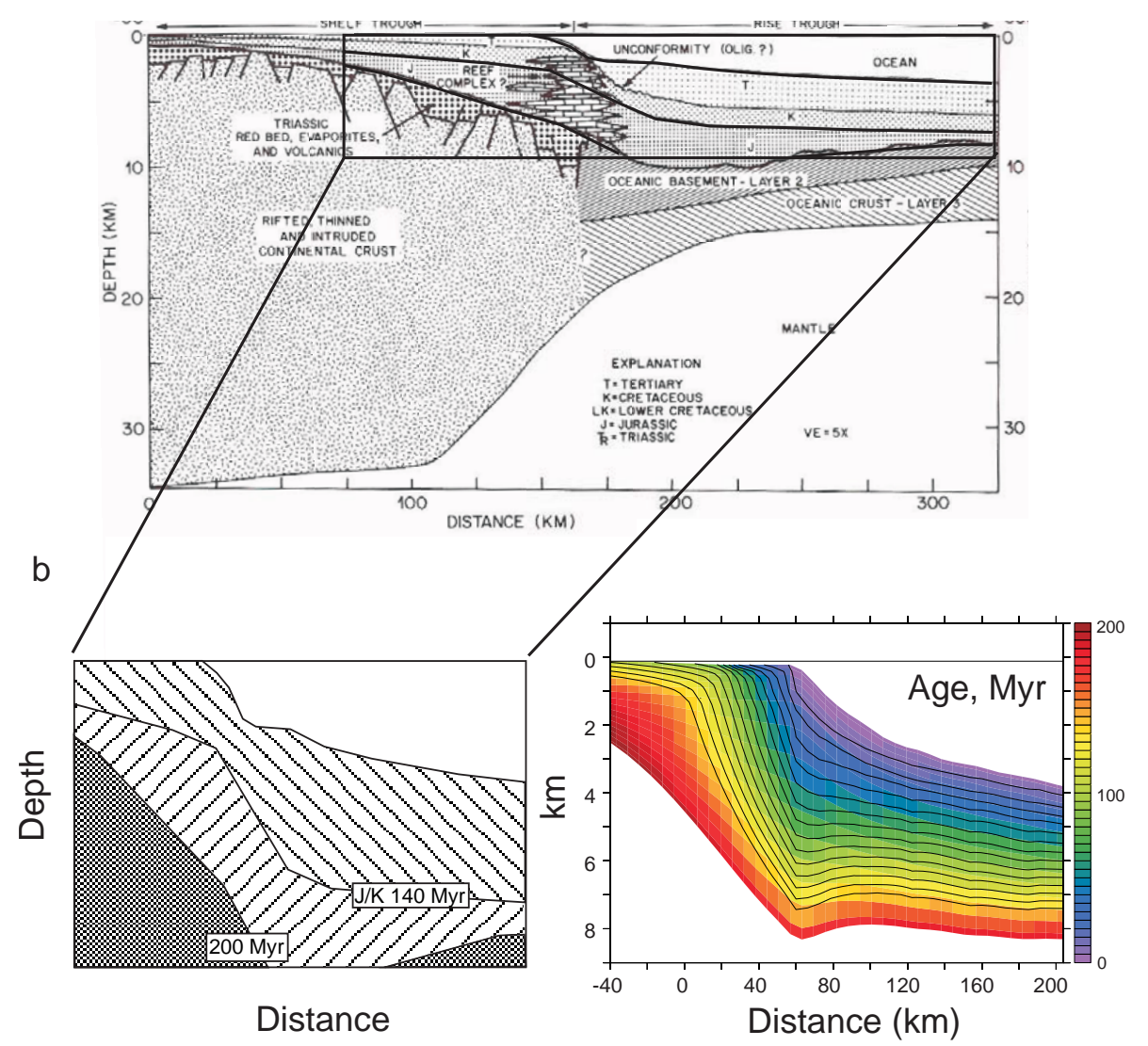

Fig. 3. (A) Sediment column constructed from a seismic section off Cape Cod, from Kennett (1982), with cutout (B) resized for comparison with model results $(\mathbf{C})$.

used for the primary settling material, but resuspended material only begins to deposit where the sea floor slope is less than $1 \%$, reflecting the difference between a turbidity flow which only stops on the plain as opposed to individual sinking particles assumed in the primary sedimenting material.

The particulate organic carbon (POC) concentration of the sediment is determined in the model as a function of water depth at the time of initial sediment deposition, as discussed under the heading Carbon Cycle. When material is resuspended from the sea floor, in contrast, its POC concentration is conserved and redeposited. Because the offshore transport is assumed to be turbidites, we assume it escapes the degradation that individual settling particles, the primary deposition, are subject to as they slowly sink through the water column. Resuspended organic carbon is assumed to be distributed among the grain size fractions of the resuspended material according to surface area, selectively concentrating (according to mass) the organic carbon into the smaller size fractions.

The sediment transport scheme is intended to be a utilitarian parameterization of sediment transport processes, rather than a mechanism-resolving model such as Sedflux (Syvitski, 2001). The scheme as we have tuned it achieves the goal of a well-defined shelf break, driven by a strong sediment depocenter just off the shelf break, and response to sea level changes that mimic the Sedpak model (Strobel et al., 1989). The accumulation rate at $2 \mathrm{~km}$ depth in the model is close to that of Blake Ridge, about $2 \mathrm{~cm} \mathrm{kyr}^{-1}$. Total sediment thicknesses and extents are comparable with a seismic image of the Atlantic margin from Kennett (1982) (Fig. 3). Model sensitivity to these sediment transport processes was gauged by altering the critical sea floor slope in sensitivity simulation Lo Slope.

\subsubsection{Sea level changes}

Sedimentation is heavily impacted by eustatic changes in sea level, with highest rates close to shore but in water that is not too shallow. Sea level changes are imposed on the simulation as a 240 million yr cycle, peaking at high sea level about 100 million yr ago and declining since then, to generally and smoothly follow the larger-scale sea level changes in the Haq et al. (1987) curve (Fig. 4). The organic carbon (POC) of the 


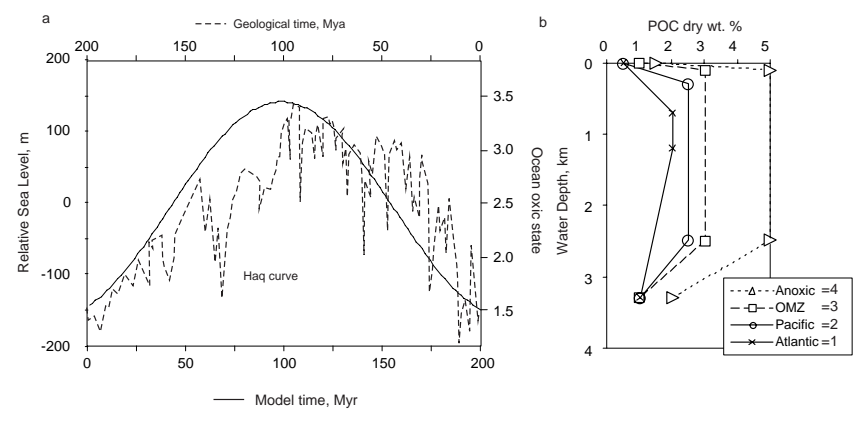

Fig. 4. (A) Sea level time variation with time imposed on the simulation, and corollary changes in the "ocean state", which drive POC deposition concentration patterns as in (B), where Atlantic and $\mathrm{Pa}$ cific represent conditions typical of the East or Northwest coasts of United States, "OMZ" is stronger oxygen minimum conditions typical of the Eastern equatorial Pacific, and Anoxic refers to anoxic conditions. Concentrations of POC in ocean sediments vary through this range and beyond; the intent here is to allow for variations that span something like the observed range.

new sediment covaries with sea level in the model (see Carbon Cycle section). Two sets of simulations were done, one which neglected time-dependent sea level changes (Table 1), and another set which included these effects (Table 2). Results in this paper will be presented as time slices from various points in the simulations, but animations of the entire runs are available as links from the figure captions.

\subsection{Pore water geophysics}

\subsubsection{Porosity and excess pressure}

The pore fluid excess pressure, which drives the pore fluid flow, is calculated from a constitutive equation in which the excess pore fluid pressure can be calculated from the porosity and the mass load overhead (Flemings et al., 2002). The idea is that there is a one-to-one relationship between the porosity of the sediment and the amount of solid load it can support. The compression of the bulk sediment by exclusion of pore water at hydrostatic pressure is governed by

$\phi_{\text {hydrostatic }}=0.38 e^{-\beta_{1} S_{\text {supp }}}+0.32 e^{-\beta_{2} S_{\text {supp }}}$

where the $\beta$-values are bulk compressibilities and $S_{\text {supp }}$ is the solid load that can be supported by sediments of that porosity. Since pore fluids are relatively close to hydrostatic, the porosity profile in the sediment column is largely governed by this relationship. We find that to produce the relatively high porosity of surface sediments and the lower porosities of the deep sediment, the column requires two exponentials with different $\beta$ values (Fig. 5b). Coefficient $\beta_{1}$ is 0.0312 and produces compaction on a depth scale of about $10 \mathrm{~km}$, representing ductile flows and recrystallization of mineral grains. The value of $\beta_{2}$ is 0.2 , producing a compaction depth scale of about $2 \mathrm{~km}$ (Fig. 5), representing the collapse of clays in the
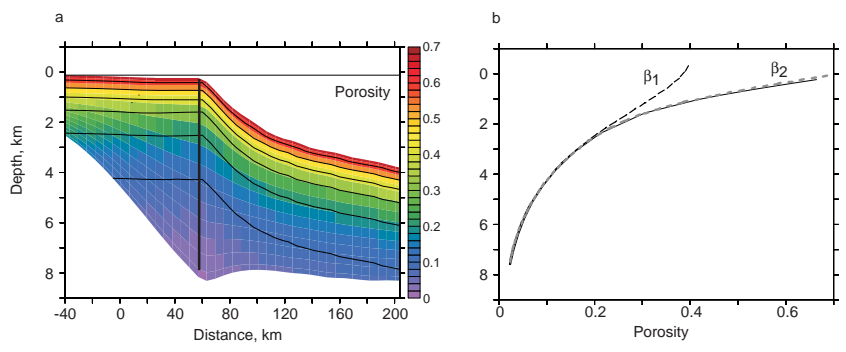

Fig. 5. Porosity at the end of the simulation, section (A) and profile (B) taken on the heavy solid line in (A): (solid line) full model solution, (long dashes) "drained" porosity contribution from $\beta_{1}$, (short grey dashes) sum of drained porosity contribution from $\beta_{1}+\beta_{2}$.

shallower sediment column. Because of the double exponential form of the constitutive equation, calculating $S_{\text {supp }}$ from $\Phi$ is an iterative calculation.

The excess pressure is then calculated as

$$
P_{\text {excess }}=S_{v}-P_{\text {hydro }}-S_{\text {supp }}
$$

where $S_{v}$ is the total load of the sediment column from all phases, and $P_{\text {hydro }}$ is the hydrostatic pressure (the load due to the fluid phase).

\subsubsection{Temperature and heat flow}

Subsurface temperatures are primarily governed by thermal conduction, a diffusional process, although fluid advection and latent heat also affect the temperature. The thermal conductivity and heat capacity are taken as a volume-weighted averages of the components: sediment, pore fluid, methane hydrate, and methane gas. A geothermal heat flux is imposed at the base of the sediment column of $70 \mathrm{~m} \mathrm{~W} \mathrm{~m}^{-2}$, with sensitivity runs spanning from 50 to $120 \mathrm{~m} \mathrm{~W} \mathrm{~m}^{-2}$.

\subsubsection{Clay dewatering}

At elevated temperatures, hydrated clays such as montmorillonite can release water to form illite. Montmorillonite is taken to be the dominant sedimenting material, and it dehydrates at temperatures above about $50^{\circ} \mathrm{C}$ (Yang, 2006) with an activation energy of $196 \mathrm{KJ} \mathrm{mol}^{-1}$. The total volume of water released in the model by this mechanism is probably an overestimate, and because the rate constant is poorly tuned in the model, the dehydrate takes place at a depth which is shallower (colder) than reality. The impact of this process is gauged in a simulation in which it is neglected called No Clay Dewatering.

\subsubsection{Permeability}

The vertical permeability $k_{\mathrm{v}}$ is parameterized as

$k_{h}=\frac{\bar{r}^{2} \phi^{3}}{180(1-\phi)^{2}}$ 

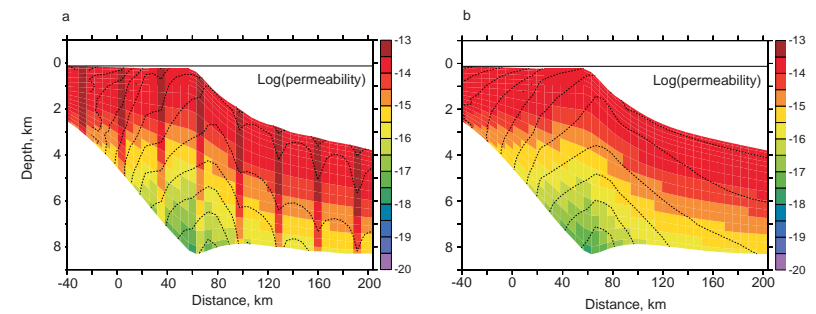

Fig. 6. Log of the vertical permeability from the end of the simulation, (A) from the Base case and (B) the No Chan case with the vertical permeable channels disabled and at lower horizontal resolution.

where $\bar{r}$ is the mean grain radius and $\phi$ the porosity (Bear, 1972). A factor of 100 anisotropy is imposed, following the example of Daigle and Dugan (2011), such that

$k_{h}=100 k_{\mathrm{v}}$

to parameterize for the effect of layers like sandy turbidites, that are unresolved in the model.

We show results of two model permeability formulations, one as presented so far, and the other with added vertical channels of enhanced permeability, such as faults, pipes, channels, and similar structures (cases Base and No Chan$n e l s$ ). The channels are situated every 5 grid cells throughout the model domain, and remain stationary as the continental margin progrades offshore through the simulation. The horizontal grid spacing is $3.15 \mathrm{~km}$, and the vertical permeability in the channel is 10 times higher than given above. This is only a crude representation of a realistic flow regime through faults and permeable channels that seem to dominate subsurface flows (Flemings et al., 2003). Most of these features would be much smaller than the grid resolution of the model can represent more realistically, although some seismic "blowout zones", disturbance of the layered sedimentary structure due presumably to gas escape from the deep sediment column, do span several kilometers in horizontal extent (Hill et al., 2004). The intent is to gauge in a qualitative way the sense and potential magnitude of the impact of heterogeneity on the flow and chemical evolution of the sediment column.

The permeabilities and the excess pressures of the two simulations at the end of the simulations are shown in Fig. 6.

\subsubsection{Darcy flow}

Fluid flow follows Darcy's law in response to the pore fluid excess pressure gradient (Athy, 1930), to find along- and across-grid velocities as

$u_{\text {Darcy }, i \rightarrow i+1}=\frac{k_{h, i}+k_{h, i+1}}{2 \mu} \frac{P_{\text {excess }, i}-P_{\text {excess }, i+1}}{\left(\Delta x_{i}+\Delta x_{i+1}\right) / 2}$

and

$w_{\text {Darcy }, j \rightarrow j+1}=\frac{k_{\mathrm{v}, j}}{\mu} \frac{P_{\text {excess }, j}-P_{\text {excess }, j+1}}{\left(\Delta z_{j}+\Delta z_{j+1}\right) / 2}$ where $\mu$ is the dynamic viscosity, $k$ the permeability, $P_{\text {excess }}$ the excess pressure, and $\Delta x$ and $\Delta z$ the grid dimensions. All of these variables except the viscosity are defined on the two grid dimensions $i$ and $j$. The velocities are defined on the cell faces.

A flow limiter in the vertical protects the calculation from numerically overstepping (for thin, permeable layers) by testing for the change in fluid pressure that would result from unimpeded Darcy flow each time step:

$\Delta P_{\text {excess }}=\Delta \phi \cdot \frac{\partial S_{\text {supp }}}{\partial \phi}$

where the derivative of the porosity/ $S_{\text {supp }}$ relation ship (Eq. 1) is stored for each grid cell as part of the iterative solution of Eq. (1) for $S_{\text {supp. If the vertical pressure gradient would }}$ change by more than $10 \%$ in a time step, a stand-in vertical velocity is calculated that limits the change to $10 \%$ :

$\Delta \phi_{\text {imposed }}=0.1\left(P_{\text {excess }, j}-P_{\text {excess }, j+1}\right)\left(\frac{\partial S_{\text {supp }}}{\partial \phi}\right)^{-1}$.

The idea is that a thin sandy layer would quickly drain, reaching zero excess pressure gradient, and the stand-in velocity is designed to achieve that end in a stable way even if the time step for Darcy flow would need to be much shorter. The $10 \%$ coefficient implies that it will take approximately 10 time steps $(5 \mathrm{yr})$ for the layer to relax to a drained condition (any faster leads to numerical instability). Most of the vertical flow in the model however is well-resolved in time, leaving the flow limiter for a few "emergency" grid points and times.

\subsubsection{Total fluid flow including sedimentation and grid stretching}

Darcy flow is defined relative to the solid grains. This is a different definition of fluid flow from the convenient and usual metric in sediment diagenesis models, which is defined relative to the sediment-water interface, which we will call $w_{\text {seafloor }}$. Formation of methane hydrate in models is very sensitive to the value of $w_{\text {seafloor }}$, upward carrying methane into the stability zone from below, or downward away from the stability zone (Buffett and Archer, 2004).

At the sediment surface, the two definitions of vertical velocity differ because the sediment surface is moving as solid and fluid material accumulates. The burial of fluid in the pores between the sedimenting solid constitutes a vertical flow across the sea floor, when the reference frame is the moving sea floor itself. At the sedient surface,

$w_{\text {seafloor }}=w_{\text {Darcy }}+\phi_{0} \cdot$ SedRate

where SedRate is the bulk sedimentation rate and $\phi_{0}$ the porosity of freshly sedimented material.

Beneath the sea floor, the calculation of $w_{\text {seafloor }}$ requires two additional terms. One is the movement from one grid 
cell to another as the vertical grid in the model stretches to fill the expanding sediment column (explained above). The fluid component of this bookkeeping "flow" is calculated as the change in elevation of a grid boundary in a time step, multiplied by the porosity.

$w_{\text {bur }}=-\frac{\partial z_{\text {boundary }}}{\partial t} \cdot \phi$

where $\partial z_{\text {boundary }} / \partial t$ represents the movement of the cell boundary.

For subsurface grid points, $w_{\text {seafloor }}$ is calculated as

$w_{\text {seafloor }}=w_{\text {Darcy }}+w_{\text {bur }}+\frac{d}{\mathrm{~d} t}\left(z_{\text {boundary }}-z_{\text {seafloor }}\right)$

The third term represents the relative movements of the seafloor and the depth of the subsurface grid cell in question. Like $w_{\text {bur }}$ and $w_{\text {Darcy }}, w_{\text {seafloor }}$ is defined on the cell faces. Numerically, the velocities are combined before any fluxes are calculated, using the net flow across a grid boundary within a given time step, rather than advecting material back and forth in multiple operations which would result in needless numerical mixing.

A subsurface value of $w_{\text {seafloor }}$ is defined relative to the moving sea floor, so that if a subsurface parcel were flowing upward just quickly enough to remain at a constant depth below the seafloor, its $w_{\text {seafloor }}$ would be defined as zero. Sections of $w_{\text {Darcy }}$ and $w_{\text {seafloor }}$ are shown in Fig. 7, and values at the sediment surface in Fig. 8.

When vertical permeable channels are added to the simulation, the channels take most of the compaction flow. The horizontal anisotropy applied to the permeability allows the sediment columns in between the channels to vent fluid into the channels for expulsion. Interestingly, for the formation of methane hydrate discussion to come, the channeled simulation finds strongly downward $w_{\text {seafloor }}$ in the grid cells in between the channels. These cells have vented their upward Darcy flow into the permeable channels, leaving the burial flux of fluid with sedimentation to drive $w_{\text {seafloor }}$ in the downward direction, where it brings methane-depleted fluid into the hydrate stability zone from above, rather than methanerich fluid from below.

\subsection{Carbon cycle}

\subsubsection{Deposition}

The carbon cycle of the deep biosphere is driven by the rain of particulate organic carbon (POC) to the sea floor. Organic carbon deposition and concentrations in surface sediments of the ocean depend on primary productivity in the ocean, runoff of terrestrial POC in some places, degradation in the water column, offshore transport, and degradation in the surface sediments which depends on the oxygen concentration of the overlying water and perhaps the temperature.
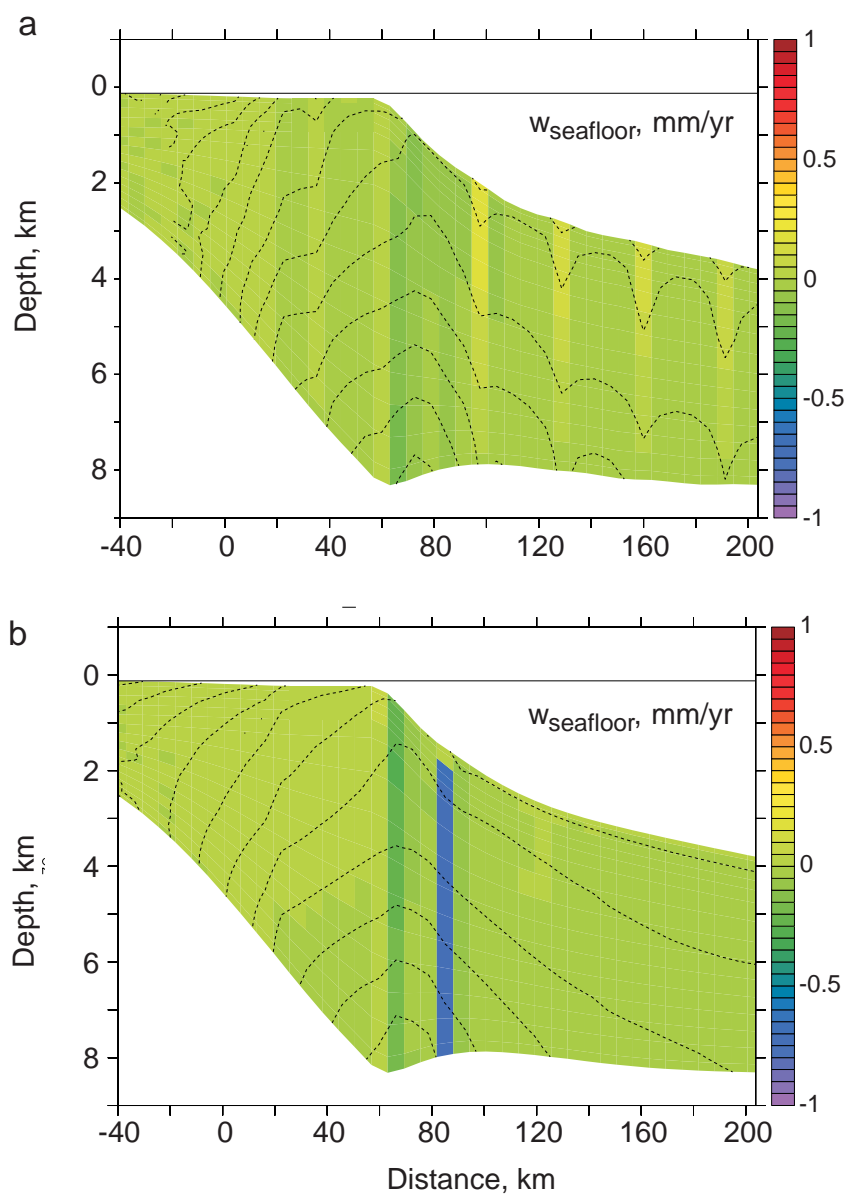

Fig. 7. Vertical velocity relative to the moving sea floor ( $\left.w_{\text {seafloor }}\right)$ for the Base (A) and No Channels (B) cases, from the end of the simulation. An animation of the simulation is archived in the Supplement and can be viewed at http://geosci.uchicago.edu/ archer/ spongebob_passive/w_seafloor.movie.gif.

Rather than mechanistically simulating that complexity, the POC concentrations and characteristics of the sedimenting material in these simulations are determined as a simple function of water depth of initial deposition and time, allowing us to control POC deposition as a boundary condition to the model rather than simulating it as a prognostic output. We used the POC parameterization to drive a scenario in which periods of high sea level have enhanced carbon preservation, a cartoonish representation of the transition from the Cretaceous to the present (Hunt et al., 2002).

Although the link between ocean oxygenation and POC deposition is not mechanistically clear or straightforward to model, we concoct and drive the model with an ocean oxygenation "index" that varies from 1 to 4 , with 1 the most oxic and 4 anoxic. Ocean state 1 is called "Atlantic", and the sedimenting POC concentration profile is comparable to sediment surface POC concentration off Cape Hatteras today (Mayer, 2002). In this state, the POC concentration is 
a
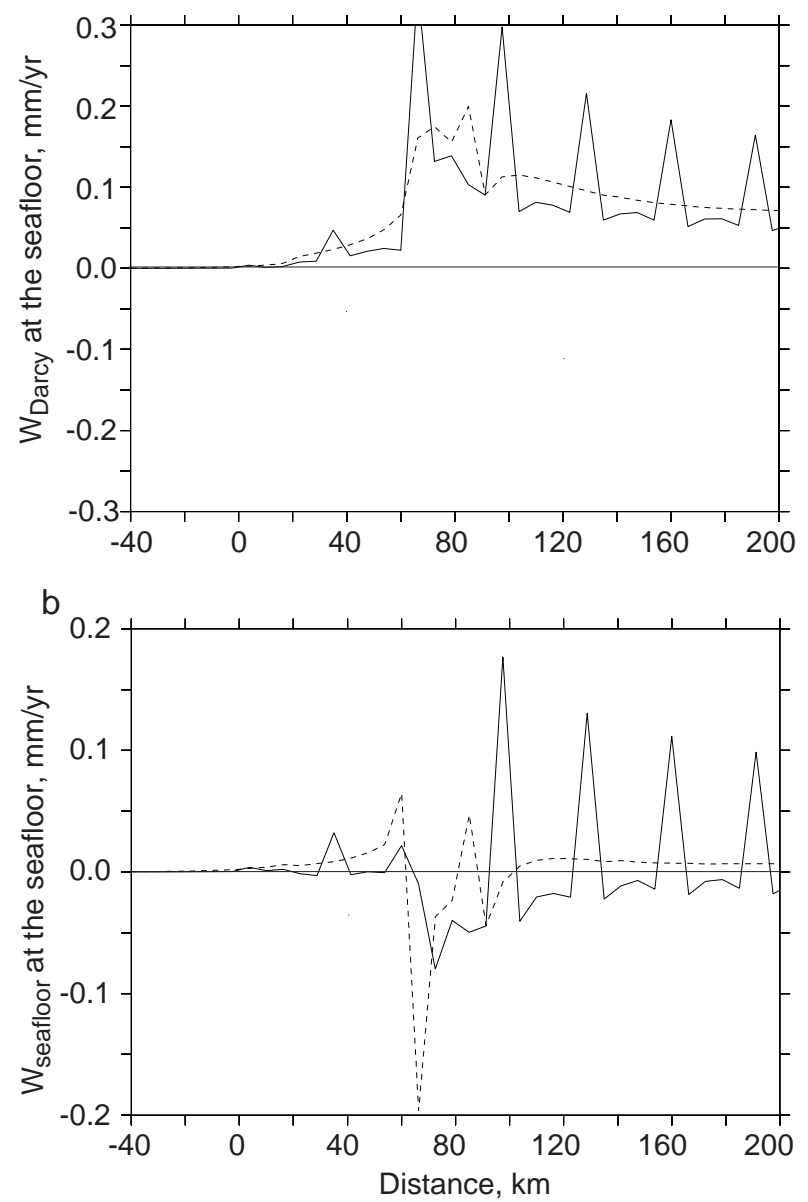

Fig. 8. Rates of vertical flow at the sea floor. Solid lines are the Base scenario, dashed the No Channel run. (A) Darcy flows ( $\left.w_{\text {Darcy }}\right)$ are upward, while (B) flows relative to the moving seafloor $\left(w_{\text {seafloor }}\right)$ can be found in both directions. An animation of the simulation is archived in the Supplement and can be viewed at http://geosci. uchicago.edu/ archer/spongebob_passive/w_seafloor_sf.movie.gif.

at most $2 \%$ dry weight $\mathrm{POC}$, with an $\mathrm{H} / \mathrm{C}$ ratio of 0.7 . The anoxic end-member buries up to $5 \% \mathrm{POC}$, with an $\mathrm{H} / \mathrm{C}$ ratio of 2 (Fig. 3b).

The ocean oxygenation index covaries with sea level and the deep ocean temperature, resulting in a scenario in which a warm high-sealevel high POC deposition ocean (100 million yr ago) transitions into the characteristics of the Atlantic ocean by the end of the simulation. For a given grid cell and time step, the POC concentrations are interpolated in depth, then interpolated in the ocean state, so that carbon deposition can vary smoothly in time, in synchrony with changes in eustatic sea level.

The impact of a persistent change in ocean oxic state on hydrate abundance was gauged in simulations with timeuniform forcing, called Atlantic, Pacific, OMZ, and Anoxic. In the time-dependent simulations, high POC concentrations
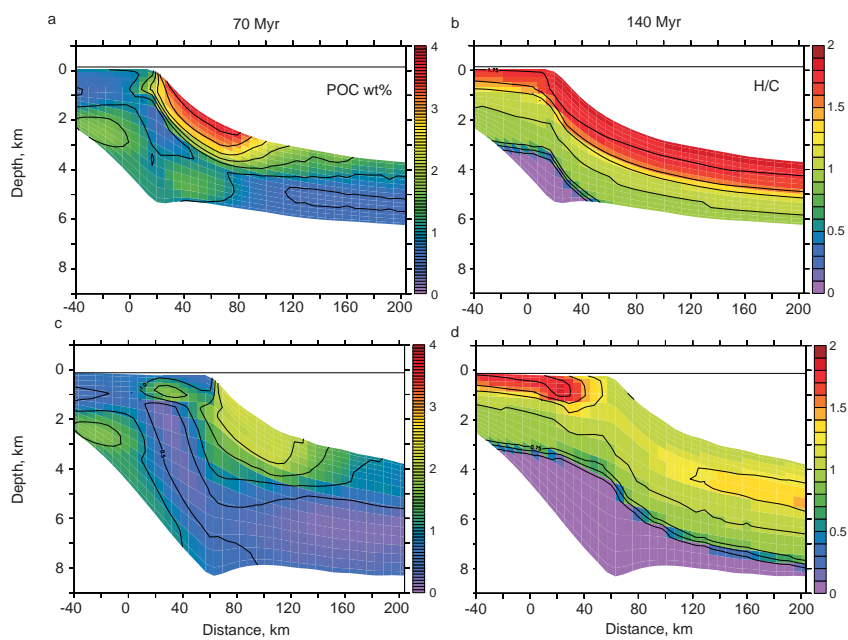

Fig. 9. POC concentrations (dry weight percent) (A and C) and H/C elemental ratio of organic matter $(\mathbf{B}$ and $\mathbf{D})$. From half-way through (A and $\mathbf{B})$ the simulation, at a period of high sea level, and ( $\mathbf{C}$ and D) at the end of the simulation, when sea level is relatively low, as today. An animation of the simulation is archived in the Supplement and can be viewed at http://geosci.uchicago.edu/ archer/ spongebob_passive/poc.movie.gif.

accumulate in a time of high sea level in the simulation, which becomes a buried feature by the end of the simulation (Fig. 9 left).

\subsubsection{Biological degradation}

Biological degradation is taken to be a function of temperature $\left(T,{ }^{\circ} \mathrm{C}\right)$, sediment age, and dissolved methane concentration.

$$
\begin{aligned}
& k_{\text {resp }}=0.5 \mathrm{yr}^{-1} \times e^{-\frac{E a}{\mathrm{RT}}} \cdot H_{\text {smooth }}\left(50^{\circ} \mathrm{C}-T, 10^{\circ} \mathrm{C}\right)^{6} \\
& \times e^{-1.1 \log (\mathrm{Age})-0.5} \times\left(\frac{35 \mathrm{mM}}{\left[\mathrm{CH}_{4}\right]+35 \mathrm{mM}}\right)
\end{aligned}
$$

where $k_{\text {resp }}$ is a first-order rate constant for POC degradation. The activation energy $\mathrm{Ea}$ is $70 \mathrm{~kJ} \mathrm{~mol}^{-1}$, resulting in a tripling in the rate with a temperature increase of $10^{\circ} \mathrm{C}$. This is a relatively moderate temperature sensitivity; Burdige (2011) argues that it could be $200 \mathrm{~kJ} \mathrm{~mol}^{-1}$, which would increase the reaction rate by a factor of 24 for an increase in temperature by $10^{\circ} \mathrm{C}$.

The second term represents inhibition of biological activity above a critical temperature of $50^{\circ} \mathrm{C}$. The formulation uses a smoothed "Heaviside" function to shut down the respiration reactions above a threshold temperature of $50^{\circ} \mathrm{C}$. This function is used several times in the SpongeBOB formulation, defined as

$$
H_{\text {smooth }}(x, \Delta x)=\frac{1}{\pi}\left(0.5 \arctan \left(\frac{x}{\Delta x}\right)\right) \text {. }
$$

This function provides a smooth transition between the on and off states (1 and 0$)$, rather than the discontinuous step 
function of the true Heaviside function. Raising the function to a power, as done here, tightens the transition, here intended to mimic a fairly strong shutdown of respiration rates when it gets too hot.

The third term represents the correlation between carbon age and its reactivity, mimicking the astonishingly wide correlation observed in nature (Hedges and Keil, 1995; Middelburg, 1989). The correlation between age and reactivity does not imply a direct or simple causation, and "priming experiments" (Bianchi, 2011) demonstrate that the age parameterization cannot be universally true. But the correlation between age and reactivity captures many orders of magnitude of variation, and seems essential to account for (Wallmann et al., 2006).

The effect of the "metabolite inhibition" effect as proposed by Wallmann et al. (2006) is represented in the last term in the formulation. Wallmann included dissolved inorganic carbon concentration in addition to methane, but for the sake of model stability and development we took the simplifying liberty of excluding DIC inhibition of methanogenesis.

Respiration is concentrated in the top $2 \mathrm{~km}$ of the sediment column, limited by temperature (Fig. 10). It is also generally focused offshore of the shelf break, except during periods of very high sea levels, during which POC can accumulate in the shelf sediments. When sea level falls, the biologically available POC in the shelf sediment burns out, leaving most of the biological activity in slope sediments, and in particular in the sediment depocenter just off the shelf break.

Model sensitivity to the respiration formulation was gauged by varying the "labile fraction" of the POC (cases Bio $10 \%$, Base (which is $50 \%$ ), and Bio $100 \%$ ).

\subsubsection{Biological methanogenesis}

The respiring carbon is assumed to produce DIC and molecular hydrogen, a transient reducing agent. If sulfate $\left(\mathrm{SO}_{4}^{2-}\right)$ is present in the pore water, the hydrogen reduces and consumes it; otherwise, it reacts with $\mathrm{CO}_{2}$ (dissolved inorganic carbon or DIC) to produce methane in reactions

$\mathrm{CH}_{\mathrm{x}}+2 \mathrm{H}_{2} \mathrm{O} \rightarrow \mathrm{CO}_{2}+(2+x / 2) \mathrm{H}_{2}$

followed by $\mathrm{CO}_{2}$ reduction

$1 / 2 \mathrm{CO}_{2}+2 \mathrm{H}_{2} \rightarrow 1 / 2 \mathrm{CH}_{4}+\mathrm{H}_{2} \mathrm{O}$

where the variable $x$ denotes the relative concentration of $\mathrm{POH} / \mathrm{POC}$ in the reacting organic matter.

The maximum efficiency with which the biologically produced $\mathrm{CO}_{2}$ can be converted to $\mathrm{CH}_{4}$ is determined by conservation of carbon, hydrogen, and oxygen from the organic matter to methane plus $\mathrm{CO}_{2}$, realizing that supplemental oxygen and hydrogen comes from $\mathrm{H}_{2} \mathrm{O}$. This maximum $\mathrm{CH}_{4}$ production efficiency is

$R_{\mathrm{CH}_{4}}=\frac{1}{2}+\frac{1}{8} \times \frac{\mathrm{POH}}{\mathrm{POC}}$ a
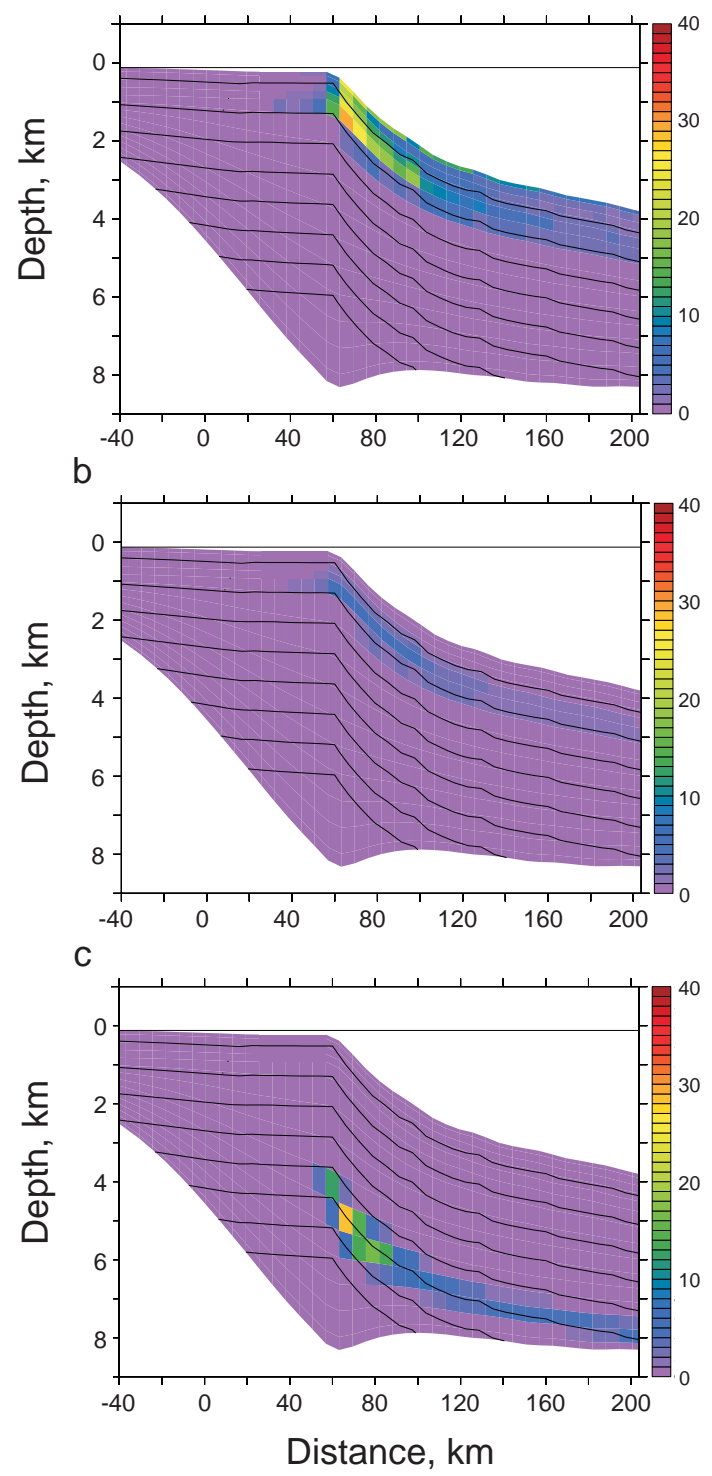

Fig. 10. Methane sources in the sediment column. (A) From biological respiration of POC. (B) From biological degradation of migrating petroleum. (C) From thermal alteration of POC. An animation of the simulation can be viewed at http://geosci.uchicago.edu/ $\sim$ archer/spongebob_passive/ch4_src.movie.gif.

which works out to $62 \%$ if the $\mathrm{H} / \mathrm{C}$ ratio of the reacting organic matter is 1 . However, carbon isotopic systematics and data, described below, will restrict the efficiency of $\mathrm{CH}_{4}$ production somewhat, as if about $20 \%$ of the $\mathrm{H}_{2}$ reacts with oxidized mineral phases, such as $\mathrm{Fe}_{2} \mathrm{O}_{3}$ rather than with $\mathrm{CO}_{2}$ to make methane, leaving an overall methane production efficiency of about $50 \%$.

Methane is oxidized in the presence of $\mathrm{SO}_{4}^{2-}$ by the anaerobic oxidation of methane (AOM) reaction. The reaction in nature is fast enough to permit just a very narrow depth range 
of overlap between the high- $\mathrm{SO}_{4}^{2-}$ pore waters in the surface sediment column and high- $\mathrm{CH}_{4}$ waters below (Burdige and Geiskes, 1983; Chatterjee et al., 2011; Davie and Buffett, 2001). The reaction in the model is based on whichever species is stoiciometrically limiting, with a effective rate constant of $5 \% \mathrm{yr}^{-1}$, unrealistically slow but numerically stable and able to eliminate simultaneous coexistence of $\mathrm{SO}_{4}^{2-}$ and $\mathrm{CH}_{4}$ in any grid cell. $\mathrm{SO}_{4}^{2-}$ is only found in a few grid cells just inside the continental shelf break. The grid resolution of the model is too coarse to resolve the details of pore water $\mathrm{SO}_{4}^{2-}$, so we leave an analysis of the behavior and impacts of $\mathrm{SO}_{4}^{2-}$ to future work.

\subsubsection{Petroleum and DOC}

The model produces petroleum based on chemical and thermal conditions. Petroleum formation in the real world is limited by the $\mathrm{H} / \mathrm{C}$ ratio of the organic matter, proceeding if the $\mathrm{H} / \mathrm{C}$ is greater than 1 , and continuing until the ratio approaches 1 . The temperature dependence of the rate constant is governed by an activation energy of $150 \mathrm{~kJ} \mathrm{~mol}^{-1}$, with a pre-exponential constant of $1 \times 10^{16} \mathrm{yr}^{-1}$. These parameters confine petroleum generation to a temperature window of $60-150{ }^{\circ} \mathrm{C}$, as inferred from the distribution of oil (Hunt, 1995).

Petroleum genesis temperatures are too warm to allow bacterial consumption, but we gauge the potential impact of bacterial respiration of petroleum by assuming that $10 \%$ of the oil is upwardly mobile at a rate of $1 \mathrm{~m}$ per thousand years. If it reaches cool enough conditions it is consumed by bacterial respiration, following the temperature and solute concentration dependence (but not the POC age dependence) of bacterial POC degradation kinetics above. The rate of methane production by this process of "secondary respiration" is shown in Fig. 10b to be deeper than POC respiration, which is more confined to the upper sediment column. The model also assumes "sloppy feeding", in which $10 \%$ of biological POC consumption goes to dissolved organic carbon (DOC). Simulations to determine the importance of these processes in the model are called No Petro and No DOC.

\subsubsection{Thermal methanogenesis}

Methanogenesis from thermal degradation of organic carbon proceeds according to an Arrhenius equation with an activation energy of $230 \mathrm{~kJ} \mathrm{~mol}^{-1}$ and a pre-exponential rate constant of $4 \times 10^{21} \mathrm{yr}^{-1}$, which produces a lifetime of a million years at about $160^{\circ} \mathrm{C}$. In contrast to the biological rate of methane production, the rate constant for thermal methane generation is very well constrained and consistent in field data, driven by the hunt for petroleum (Hunt, 1995).

The rate of methane production is taken to be this rate constant multiplied by the concentration of particulate organic hydrogen, $\mathrm{POH}$. The POC inventory decreases by $1 / 4$ of the decrease in $\mathrm{POH}$ during methanogenesis. The distribution of
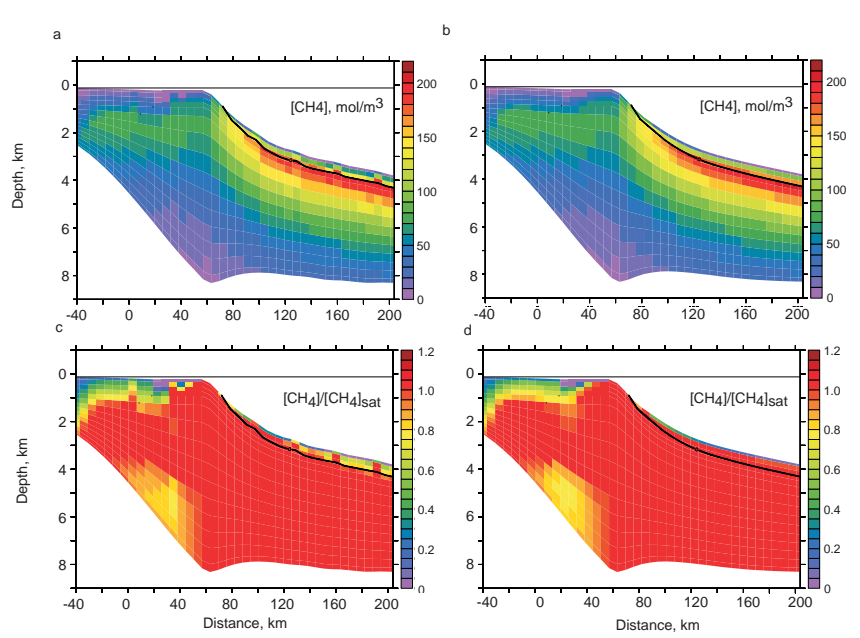

Fig. 11. Concentration of dissolved methane plotted in moles $\mathrm{m}^{-3}$ (A and $\mathbf{B})$, and relative to saturation ( $\mathbf{C}$ and D). Base model run (A and $\mathbf{C}$ ), and No Channels (B and $\mathbf{D})$. An animation of the simulation is archived in the Supplement and can be viewed at http://geosci. uchicago.edu/ $\sim$ archer/spongebob_passive/ch4.movie.gif.

the $\mathrm{H} / \mathrm{C}$ ratio in the sediment column (Fig. 9 right) is primarily driven by the effects of changing ocean chemistry (anoxia) and thermogenic degradation. The $\mathrm{H} / \mathrm{C}$ ratio approaches zero as the carbon matures, and the decrease in $\mathrm{H}$ directly limits the production of methane in the model.

\subsubsection{Methane bubbles and hydrate}

The dissolved methane concentration is compared with the solubility of dissolved methane, relative to the two possible other phases of gas bubbles or hydrate, in Fig. 11. Hydrate or bubbles both release or take up methane from the dissolved phase. Disequilibria in the three-phase methane system is restored toward equilibrium by conversion to or from bubbles or hydrate with a numerically-tractable but ad-hoc time constant of $1000 \mathrm{yr}$. This unrealistically slow time constant, a compromise that should doubtlessly be higher for future detailed simulations, permits the dissolve methane concentration to reach unrealistically high supersaturation values ( $\Omega=1.2$ in Fig. 11), but since dissolved methane is a transient intermediate species in the pathway POC to $\mathrm{CH}_{4}$ to bubbles, the rate of bubble formation will be determined by methaneogenesis, and the dissolved methane concentration in the steady state will grow in to fulfill that balance, leaving only the question of whether the altered $\mathrm{CH}_{4}$ concentration changes some other aspect of its dynamics, by diffusing more quickly for example.

When the precise depth of the stability boundary (determined by depth interpolation) falls within a grid cell, the nongaseous $\mathrm{CH}_{4}$ is allocated into bubbles and hydrate in proportion to the volumes of the two zones, and the concentrations of the phases, for purposes of advection and diffusion, are calculated using the partial grid cell volumes. This prevents 
a
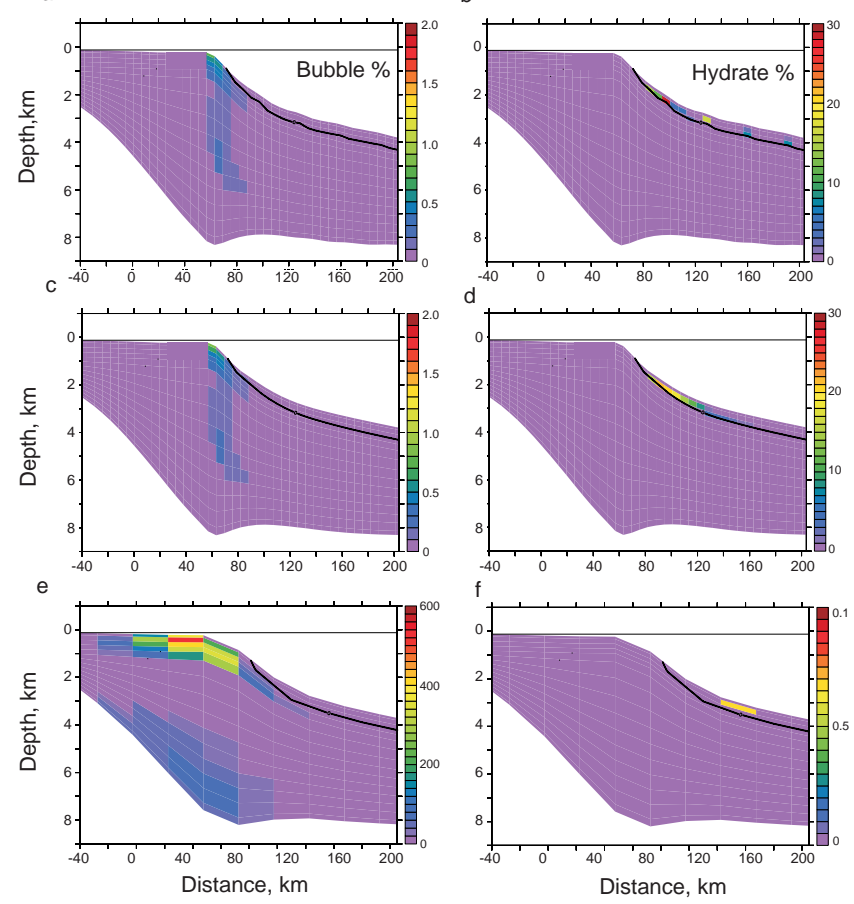

Fig. 12. Bubbles $(\mathbf{A}, \mathbf{C}, \mathbf{E})$ and hydrate $(\mathbf{B}, \mathbf{D}, \mathbf{F})$ (volume percent of pore space). From the Base model (A and B), the No Channels model (C and $\mathbf{D})$, and with bubble migration disabled $(\mathbf{E}$ and $\mathbf{F})$. An animation of the simulation is archived in the Supplement and can be viewed at http://geosci.uchicago.edu/ archer/ spongebob_passive/bubbles.movie.gif.

a numerical artifact that otherwise appears as the depth of the stability boundary crosses through the coarse numerical grid of the model.

The methane cycle in the SpongeBOB requires gas-phase mobility in the sediment column. If bubbles are not allowed to migrate, gas completely fills some parts of the sediment column pore space (Fig. 12c). Gas volume in the pore space of the model currently and unrealistically has no impact on the fluid pressure or flow, allowing unlimited gas accumulation to fill up to $200 \%$ of the original pore volume. That much methane simply has to go somewhere.

In a basin-scale sense, gas mobility comes as no surprise. The view from petroleum geology is that, on geologic time scales, sediment columns are permeable to gas except under permafrost soils and evaporites, which overlay the largest gas accumulations in the world in Siberia and the Middle East, respectively. Other parts of the world, for example the North Sea, are vastly enriched in oil relative to the expected amount of gas were it retained (Hunt et al., 2002). On the smaller spatial scales of structural hydrate deposits, such as at Hydrate Ridge (Treguer et al., 1995), gas migration is also apparent. Gas migration is a fundamental part of the Liu and Flemings (2007) model to explain the seismic "wipeout zones" and observed methane emissions from the seafloor within the hydrate stability zone (Hill et al., 2004).

In contrast, for modeling "stratigraphic" methane hydrate deposits typical of most of the continental margin, gas migration is typically neglected or assumed to be small (Burdige, 2011; Chatterjee et al., 2011; Davie and Buffett, 2001; Davie and Buffett, 2003a; Davie and Buffett, 2003b; Garg et al., 2008; He et al., 2011; Liu and Flemings, 2007; Xu, 2004). These one-dimensional methane hydrate models span a domain a few hundred meters below the stability zone boundary and assume that the bubbles there are immobile. This is not a priori wrong; it could be that gas transport is only important in the structural hydrate deposits, more obviously associated with faults and channels. However, we do find that methane hydrate formation in SpongeBOB is strongly driven by upward migration of gas, the same gas flux as is required to evacuate excess gas from the deep sediment column.

Gas tends to form if the dissolved concentration of the gas exceeds the Henry's law solubility, a function of the pressure of the gas. Surface tension raises the pressure of the gas phase somewhat over that of the pore fluid, but the differences are small relative to the overall pressure, so the impact of excess gas pressures on methane solubility have been neglected in the model. Bubbles typically grow, in cohesive sediments, by fracturing the sediment matrix (Boudreau et al., 2005; Jain et al., 1995), requiring further excess pressure that is a function of sediment properties such as fracture strength. With a continuous source of methane, dissolved methane concentrations can rise until Henry's law produces gas at whatever pressure is required to create the bubble.

It is another issue to understand the upward mobility of the gas, as opposed to its growth in place. Even at pressures near the base of the sediment column, the compressed gas is buoyant, manifesting as an upward body force that intensifies as the bubble rises and decompresses. One source of excess pressure at the top of a bubble is the hydrostatic pressure difference between the top and the bottom of the bubble (Jain and Juanes, 2009). However, for a bubble several kilometers deep in the sediment column to break through the sediment column by this mechanism, the bubble would have to several kilometers tall, to get the excess pressure at the top of the bubble high enough to break through the sediment column. Presumably gas migration from the deep sediment resembles gas blasting through a pipe more than it does a long bubble contemplating rising. The gas can manufacture its own means of escape by building up to lithostatic pressure, possibly venting episodically.

Laboratory experiments find a critical gas saturation (pore volume fraction) of about $10 \%$ where gas begins to mobilize (Leas et al., 1950), and values of 1-2\% are often assumed in models for natural gas in wells (Reagan and Moridis, 2007). Higher gas saturations connect bubbles together, crossing the hydrostatic pressure gradient as well as providing a pathway for the gas to flow, which is important because gas is much less viscous than pore water, 
even when it is compressed. The standing stock of bubbles in the sediment column is another transient intermediate reservoir for methane in the pathway $\mathrm{POC} \rightarrow$ dissolved methane $\rightarrow$ standing gas bubbles $\rightarrow$ migrating gas. In the steady state, the standing gas bubble reservoir will find the concentration at which the methane fluxes balance. The essential balance is between methanogenesis and upward gas flux in the model. A bias in the bubble flux parameterization would result in an incorrect standing bubble concentration but no error in the bubble flux itself, unless the bubble concentration leads to some distortion of the methane budget, such as by burial of gas.

We have adopted a parameterization of bubble migration that depends on the bubble fraction in pores

$\mathrm{CH}_{4}$ loss $=H_{\text {smooth }}\left(F_{b}-10 \%, 5 \%\right)^{3}$

where again the $H_{\text {smooth }}$ is a smoothed version of a Heaviside function. The bubbles escape as their concentration approaches or exceeds a critical pore volume fraction of $10 \%$. In practical terms, the bubbles in SpongeBOB only fill at most $1-4 \%$ of the pore space, because the loss rate, however slow, is able to keep up with production, even when the saturation value is much less than the parameterized critical value.

Rather than resolve the rise of the gas through time, we instantaneously redistribute some of the $\mathrm{CH}_{4}$ lost as migrating bubbles into the dissolved phase to grid cells above where the bubble first started moving. This approach is analogous to the treatment of sinking plankton in the water column of many ocean chemistry models, in which the sinking organic matter is assumed to reach some mean distance before instantaneously redissolving. The bubbles once in motion rise through the sediment until they encounter pore water that is undersaturated with respect to dissolved methane, at which point the upward flow is attenuated with height as

$\mathrm{CH}_{4}$ flux $(z)=\mathrm{CH}_{4}$ flux $(0) \cdot e^{-z / z_{\text {scale }}}$

where the value of the scale height parameter $z_{\text {scale }}$ is taken to be 500 meters in the high-resolution run, but varied to 100 and $2000 \mathrm{~m}$ in two of the sensitivity runs (called Bubb_100m and Bubb_2k). The methane cycle in the model in general, except for the standing bubble inventory, is not very sensitive to the bubble mobility parameterization, but the methane hydrate inventory is extremely sensitive to what happens to the gas after it begins moving.

The distribution of bubbles resulting from these assumptions is shown in Fig. 9. A standing crop of bubbles is sustained by respiration in the upper sediment column, and there is a column of bubbles carrying methane from the thermogenic zone up toward the sediment surface. Thermogenic methane in the model systematically evades the hydrate stability zone, because the sediment column is only deep enough to reach high enough temperatures when the top sediment column has nearly reached the sea surface, so that there

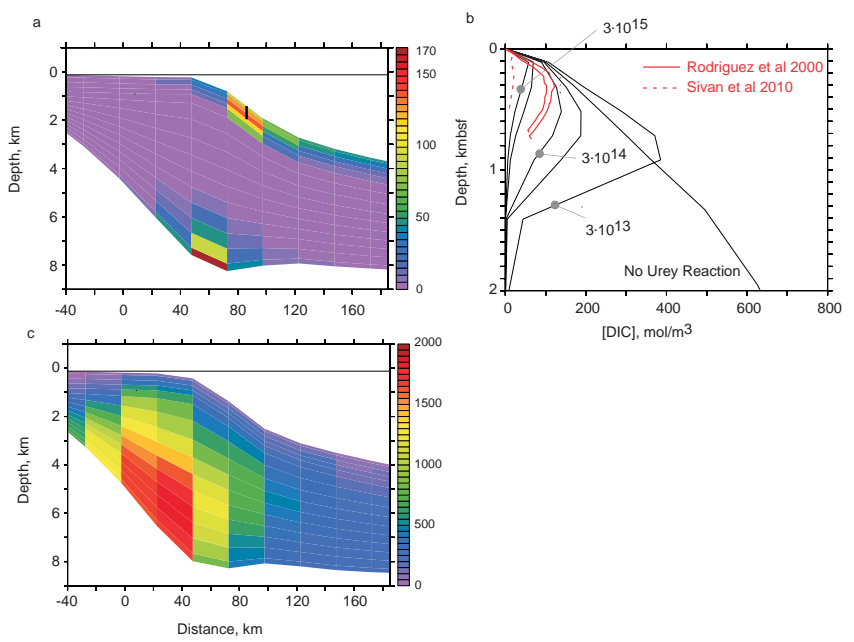

Fig. 13. DIC concentrations, moles $\mathrm{m}^{-3}$. (A) Base case section, (B) Base case profiles compared with data in red from Blake Ridge ODP sites 994 and 997 (Rodgiruez et al., 2000)and the West African margin Sivan et al. (2007), and (C) with Urey reactions that consume $\mathrm{CO}_{2}$ disabled (note change in color scale from A). An animation of the simulation is archived in the Supplement and can be viewed at http://geosci.uchicago.edu/ archer/ spongebob_passive/dic.movie.gif.

is in general no hydrate stability zone over thermal methane production in the model (Fig. 9). This geophysical mechanism could lead to a general bias toward biogenic rather than thermogenic methane in deep margin hydrate deposits.

\subsubsection{DIC and subsurface weathering}

Measurements of the titration alkalinity of pore waters (a reasonable facsimile to DIC under $\mathrm{pH}$-neutral conditions) from Blake Ridge reach fifty times higher than the ocean value within the top few hundred meters, but then either decrease to half that by the deepest samples measured, about 700 mbsf (Rodgiruez et al., 2000). A similar decrease with depth was documented from the West African margin (Sivan et al., 2007).

In the model, if $\mathrm{CO}_{2}$ is allowed to accumulate in deep sediment pore water without a compensating sink, the DIC concentration of the model increases monotonically to bedrock (Fig. 13b and c). The difference can be explained as a chemical weathering or carbonate formation reaction (Wallmann et al., 2008), such as

anorthite $+\mathrm{CO}_{2} \rightarrow$ kaolinite $+\mathrm{CaCO}_{3}$.

Throughout the upper sediment column, the equilibrium concentration of dissolved $\mathrm{CO}_{2}$ based on this equilibrium is much lower than the measured concentrations. At low temperatures typical of the surface of the Earth or the upper sediment column, this reaction is too slow to reach 
equilibrium, but at a high enough temperature the reaction proceeds quickly as the metamorphic decarbonation reaction. We treated this reaction as a first-order uptake in DIC. This neglects the impact of the alkalinity or $\mathrm{pH}$ of the solution on the $\mathrm{CO}_{2}$ concentration, but the constancy of porewater alkalinity/DIC ratios (Sivan et al., 2007) and $\mathrm{pH}$ make this seem a reasonable assumption. The reaction as written will affect the concentration of calcium, $\mathrm{Ca}^{2+}$, but it is not calcium limited unless there is a shortage of unweathered igneous calciumbearing rock. The model assumes equilibrium with $\mathrm{CaCO}_{3}$, rather than try to resolve the porewater chemistry into its components alkalinity, calcium, and DIC.

The kinetics of DIC uptake are taken to be a function of temperature as

$k_{\text {urey }}=k_{\text {urey }_{0}} e^{\frac{-E a}{\mathrm{RT}}}$

where the activation energy $E a$ is $120 \mathrm{~kJ} \mathrm{~mol}^{-1}$, increasing the rate constant by a factor of five in response to a temperature increase of $10^{\circ} \mathrm{C}$. The slowest pre-exponential multiplier we tried was $3 \times 10^{13} \mathrm{yr}^{-1}$, which produces a reaction timescale of about $10^{8} \mathrm{yr}$ at $15^{\circ} \mathrm{C}$, so that essentially nothing happens in surface sediments, to a time constant of $1000 \mathrm{yr}$ at $100^{\circ} \mathrm{C}$. We also show profiles of model DIC concentration with faster uptake kinetics, by factors of 3 spanning two orders of magnitude.

The model profiles (Fig. 13b) are compared with alkalinity data for ODP sites 994 and 997 on the Blake Ridge (Rodger, 2000). Both the peak concentration and the depth of the peak are best simulated by the model with an intermediate rate constant of the range we tried, $3 \times 10^{14} \mathrm{yr}^{-1}$.

For all runs with nonzero Urey reaction rate constant, there is a drawdown in DIC concentration with depth. The similarity to measured concentrations lends strong support to the significance of this reaction to sediment pore water DIC. It is no surprise that carbonate formation occurs within the sediment column (Rodger, 2000), but it is interesting to note the impact that this process has on measured DIC concentrations.

Also in all weathering runs, the concentration of DIC in sediments warmer than $100^{\circ} \mathrm{C}$ in the model is effectively controlled by equilibrium, determined from thermodynamic data for the phases in the weathering reaction. The highest DIC levels in the simulation are found in the hottest, deepest sediments due to the effect of temperature on the equilibrium condition, the beginnings of metamorphic decarbonation (Fig. 13a). At temperatures between about 50 to $100^{\circ} \mathrm{C}$, the equilibrium DIC concentration is relatively low, but the reaction kinetics in the model are still fast enough for equilibrium to be reached, pulling DIC concentrations down in that depth range, and isolating the high DIC concentrations in the hottest sediments from reaching the sediment surface.

\subsubsection{Carbon isotopes}

The model tracks parallel tracers representing the stable carbon isotopes in DIC and $\mathrm{CH}_{4}$. Using methodology used in
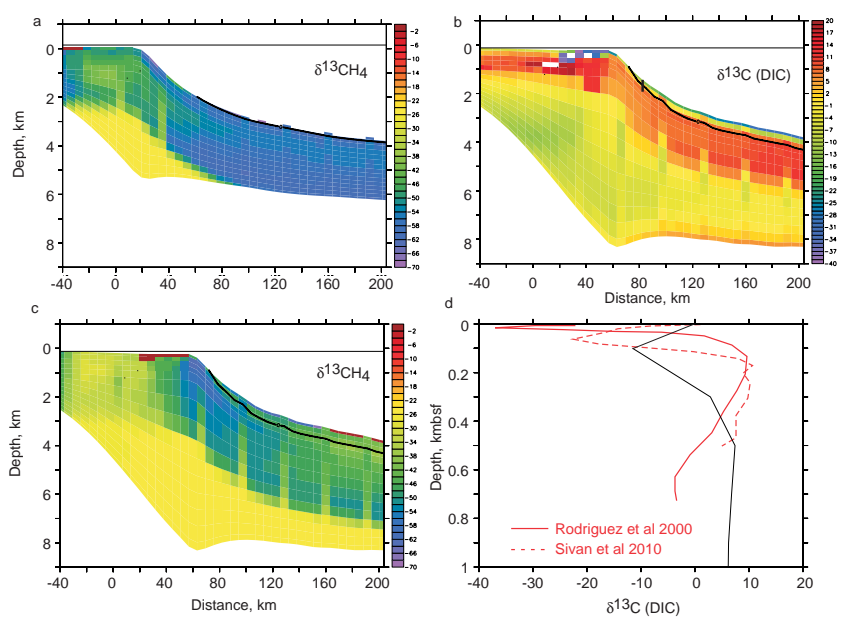

Fig. 14. Carbon isotopic composition of methane from half-way through (A), and at the end of the simulation (C). (B) is the $\delta^{13} \mathrm{C}$ of DIC at the end of the simulation, compared with data from Blake Ridge ODP sites 994 and 997 (Rodgiruez et al., 2000) and the West African margin Sivan et al. (2007) (D). The model lacks the resolution to capture the isotopically light spike just below the sea floor, but the deep isotopic composition matches well. Animations of this plot is archived in the Supplement and can be viewed at http: //geosci.uchicago.edu/ $\sim$ archer/spongebob_passive/del13.movie.gif.

ocean (Maier-Reimer et al., 1982) and sediment modeling (Jorgensen, 1978), the isotopologs undergo the same advection, diffusion, and chemical reaction operators, but with offsets in the reaction rates corresponding to the fractionation factors. Rather than try to numerically resolve the large relative concentration differences between the isotopes, the isotopic standard ratio for all isotopic systems is defined to be 1 meaning equal concentration of both isotopes at $0 \%$. The results, presented in \%o deviations from the standard ratio, are directly comparable with isotopic ratios of natural samples presented relative to their separately defined standard ratios (PDB for $\delta^{13} \mathrm{C}$, for example).

The isotopic boundary conditions are that the DIC in the ocean is assumed to be $0 \%$, and organic matter is assumed $-25 \%$. Organic matter is respired to DIC without fractionation. $\mathrm{CO}_{2}$ reduction carries a fractionation of $-90 \%$ at $0{ }^{\circ} \mathrm{C}$, dropping to about $-55 \%$ at $50^{\circ} \mathrm{C}$ (Whiticar and Faber, 1986). Thermogenic methane is assumed to have the isotopic composition of organic matter. Diffusion and anaerobic oxidation of methane (AOM) also fractionate the carbon isotopes.

The isotopic composition of DIC in the sediment column (Fig. 14) is lightened by degradation of organic matter, but then pulled heavier by extraction of isotopically light $\mathrm{CH}_{4}$. As a result, the isotopic composition of DIC or alkalinity in porewater samples starts near $0 \%$ at the sediment surface, then trends light in the near subsurface due to respiration in the non-methanogenesis zone, then gets heavier, reaching a maximum value of about $+10 \%$ (Fig. 14). These features 
are mimicked by the model, but the degrading effect of the coarse grid resolution can clearly be seen in the broadening and attenuation of the subsurface negative isotopic excursion.

Sivan et al. (2007) interpret the maximum $\delta^{13} \mathrm{C}$ of the DIC as an indicator of the rate of methanogenesis, but it turns out to be more sensitive in the model to the relative partitioning of respired carbon between DIC and methane. If the respired carbon has an isotopic composition of $-25 \%$, and the fractionation between $\mathrm{CH}_{4}$ and DIC at some temperature were $60 \%$, for example, then a balance of about $50 \%$ methane versus DIC would tend to produce DIC at an isotopic composition of $+10 \%$. In time, this source composition dominates the pore water value. Model experiments did not show a sensitivity of $\delta^{13} \mathrm{C}$ in DIC to the overall methanogenesis rates, but it does respond to the relative $\mathrm{CH}_{4}$ production efficiency. The best fit seems to require some loss of $\mathrm{H}_{2}$ in the pathway, as if by reduction of mineral phases.

\subsubsection{Iodine-129}

Iodine-129 has been used as a tracer for the age of the degrading organic matter in a sediment column (Fehn et al., 2000). Iodine-129 is produced by cosmic ray spallation in the atmosphere and it has a 22.8 million yr e-folding lifetime. Radioactive and stable isotopes of iodine are incorporated into biological material, and released to the pore water as the carbon degrades biologically. Iodine released by older organic carbon will have less iodine- 129 because of radioactive decay. In the model, both stable and unstable iodine are carried with the pore flow and are subject to diffusion along with the rest of the dissolved tracers.

Fehn et al. (2000) measured $\mathrm{I}^{129}$ ages 55 million yr old in pore waters of solid sediment that was 1.8 to 6 million yr old, a difference of about 50 million yr, which they interpreted as indicative of 50 million yr old carbon degrading.

Iodine-129 seems like a very rich tracer in the SpongeBOB model, indicative of the history of the accumulation of the sediment column and the expulsion of fluid from it (Fig. 15). Variations in $\mathrm{I}^{129}$ age arise from compaction-driven fluid flow. When fluid flow is prevented in the model, the iodine ages correspond to the sediment ages (Fig. 15d). When fluid flow is enabled but without the permeable channels (Fig. 15b), there are iodine ages 60 million yr older than the solid ages at its maximum, located in mid-column sediments under the deep continental slope, along with $\mathrm{I}^{129}$ ages less than the solid age in its minimum under the continental shelf. This pattern persists when permeable vertical conduits are available, with a superimposed pattern that the $\mathrm{I}^{129}$ ages within the conduits are older than in the surrounding lowflow columns (Fig. 15c). The old $\mathrm{I}^{129}$ ages "grow in" as the continental margin ages (compare Figures 15a and c).

The iodine ages in the depth range of Blake Ridge in SpongeBOB never get as old as Fehn et al. (2000) measured at Blake Ridge. The values in the conduits reach 20 million yr old, while Fehn measured 50 million yr. The model results

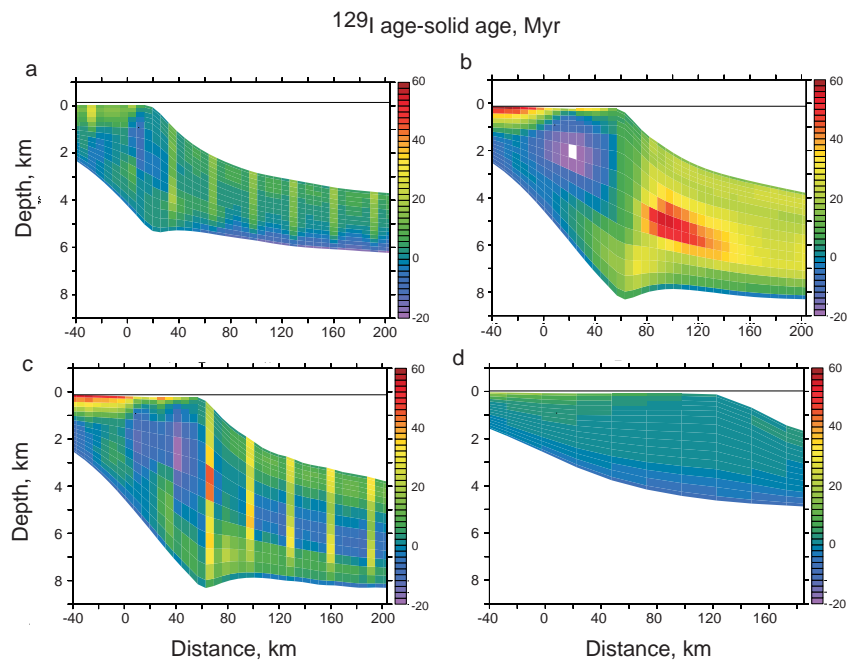

Fig. 15. Iodine-129 porewater age - sediment age, in millions of years. With permeable channels $100100 \mathrm{Myr}$ of model time, (A) and $200 \mathrm{Myr}$ (B), without permeable channels (C), and (D) with pore fluid flow disabled, $t=30$ myr instead of 200 myr for the other simulations. Animations of this plot is archived in the Supplement and can be viewed at http://geosci.uchicago.edu/ archer/ spongebob_passive/i129.movie.gif.

suggest that the old $\mathrm{I}^{129}$ ages measured at Blake Ridge probably have more to do with pore fluid flow than with the age of respiring organic carbon. They also suggest that Blake Ridge pore water geochemistry may be affected by focused subsurface flow, such as crudely approximated by the model, and thus would over-represent the abundance of methane hydrate along margin sediments overall (which cannot all be the subject of focused upward flow).

\section{Model sensitivities}

\subsection{Scenario runs}

In addition to the "Base HR" and "No Conduits HR" cases, a series of sensitivity simulations were done, at lower spatial resolution of only 10 grid points horizontally instead of 40 . The setup, intent, and summary of the conclusions from the sensitivity runs are described in Tables 1 and 2, and the resulting methane hydrate inventories shown in Fig. 16a and b. One suite of simulations was forced by time-invariant forcing, comprising sea level, ocean "oxic" state (POC deposition patterns), and temperature with variations as described in Table 1. These allow a clearer diagnosis of the model sensitivity to these variables. Another suite of simulations imposes time-varying forcing shown in Fig. 3, as described in Table 2. The time evolution of sea level, POC inventory, methanogenesis rates, and hydrate inventories are shown in Fig. 16c for the two representative cases, the Base case, which including the sea level changes, and case $T 0$, which does not. 

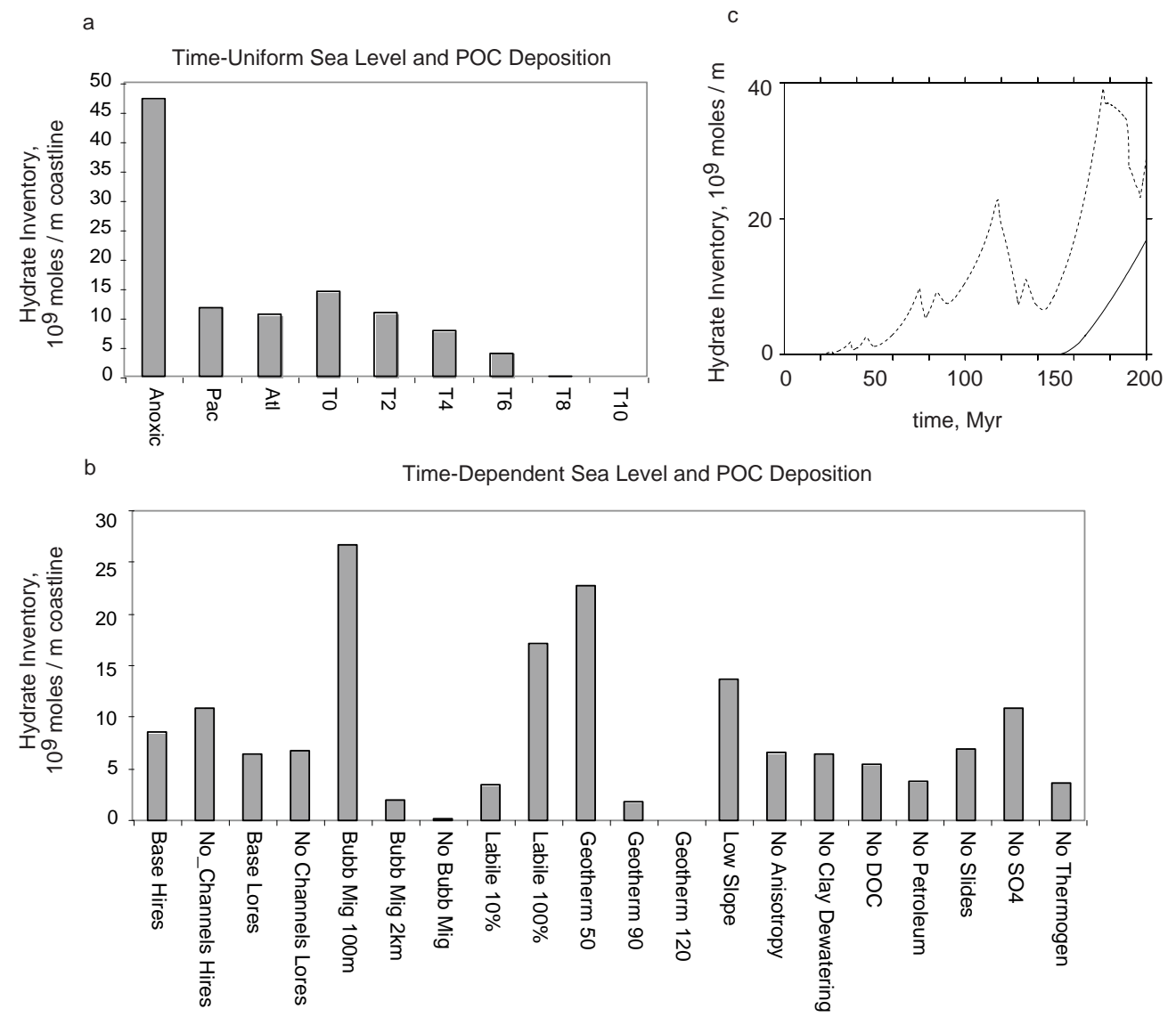

Fig. 16. Results of model sensitivity runs. (A and B) Hydrate inventory at the end of the simulation, (A) for the time-uniform forcing runs and (B) for the time-varying forcing runs. (C) The time trajectory of hydrate inventory, solid line is Base (time-varying), dashed line is simulation T0 (time-uniform).

\subsection{Sensitivity to temperature}

The effect of ocean temperature on model hydrate inventory is shown in Fig. 17a. These are from time-invariant suite of runs, with temperature a function of water depth only. The inventory of hydrate decreases roughly linearly with temperature, finally reaching zero hydrate with a warming of $8^{\circ} \mathrm{C}$. The active margin simulations (presented in the companion paper) have a similar temperature sensitivity to the passive case. The SpongeBOB model is significantly less sensitive to temperature than the Davie and Buffett (2001) onedimensional model (Fig. 17a). These are essentially equilibrium calculations, comparable to those of Buffett and Archer (2004).

The difference is probably due to the fundamentally different processes controlling vertical methane fluxes between the two models. The 1-D model relies on the transport of dissolved-phase methane into the stability zone. In a warmer ocean, the stability zone gets thinner, which increases the diffusive loss of dissolved methane in that model by requiring the diffusive gradient to be steeper. This had the impact in the Buffett and Archer (2004) simulations of restricting the formation of hydrate to regions of higher POC content, reducing the ocean's ultimate equilibrium inventory of methane nearly completely with $3{ }^{\circ} \mathrm{C}$ of warming. Methane trapping in the stability zone, when it is transported by bubbles in SpongeBOB, would also be affected by a change in the stability zone thickness, but the mechanism is different and so it is not surprising that the two models would have different temperature sensitivity.

The model also predicts a very strong hydrate dependence on the value of the geothermal heat flux (Fig. 17b), with more hydrate in lower heat flux regimes. A sensitivity as strong as this ought to be detectable in observational data.

\subsection{Sensitivity to POC}

The sensitivity of the hydrate inventory to POC can be seen in the model response to changes in the labile fraction of the sedimenting POC (Fig. 17c). In practice, the respiration zone is thin enough that the POC is not often limited by depletion of the labile POC fraction, so the labile fraction acts like a scaling of an apparent bulk POC degradation rate constant. With the tight correlation between organic carbon age and 


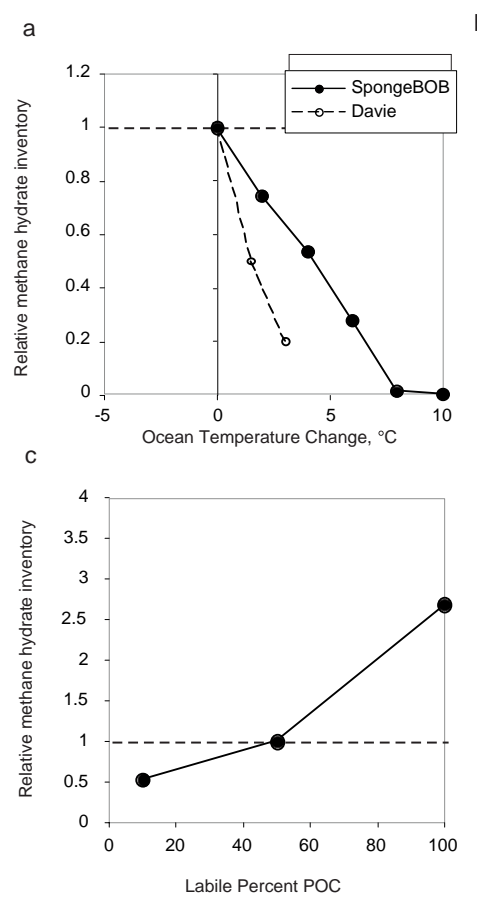

b
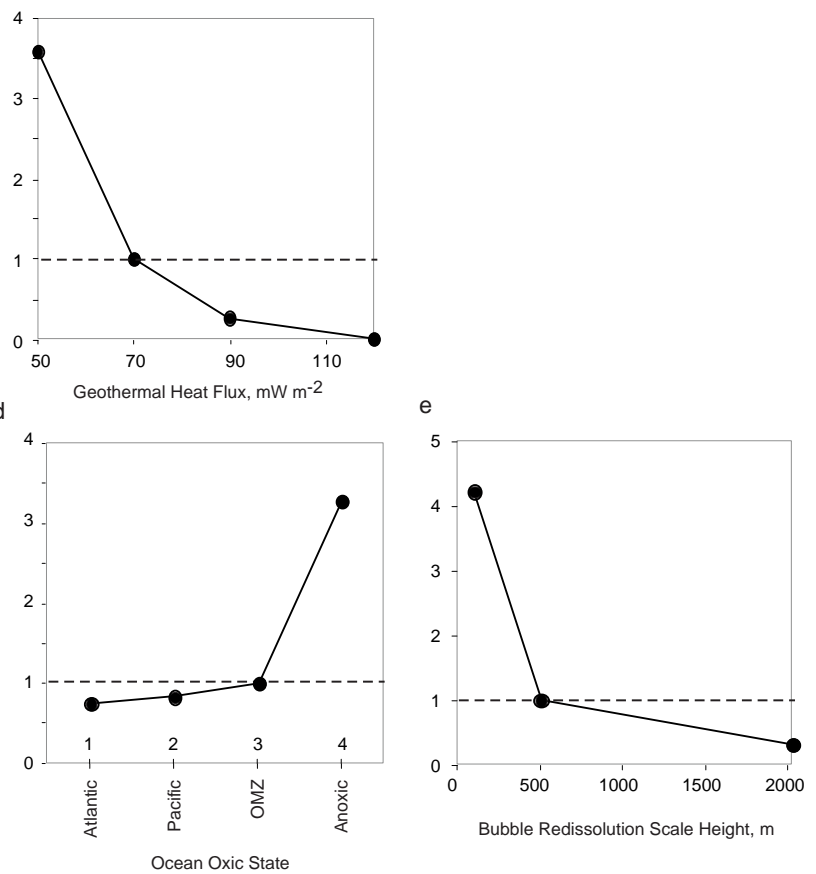

Fig. 17. Summary of model sensitivities. Y-axis is the hydrate inventory relative to the appropriate base case $=1$. (A) Temperature, $(\mathbf{B})$ geothermal heat flux, (C) percent labile fraction of depositing POC, (D)ocean oxic state (see Fig. 3), and (E) migrating bubble re-dissolution scale height.

reaction rate (Middelburg, 1989), this range in effective POC degradation rate constants might optimistically be viewed as a range in the uncertainty in the POC degradation rates.

The model sensitivity to POC deposition was also gauged using time-invariant forcing, by varying the "ocean oxic state" variable through the spectrum from "Atlantic" (low POC concentrations in surface sediments, state $=1$ ) to " $\mathrm{Pa}$ cific" (2), "OMZ" (3), and "Anoxic" (4). The range in sediment surface POC concentrations is intended to bracket something of the range in the ocean, and Figure 17d shows the sensitivity to that range. Changes in POC deposition have a much greater capacity to increase the hydrate inventory than changes in temperature could, because the ocean is near freezing and it can mostly warm from here.

The ability of high POC to overcome warm temperatures to produce hydrates in the geologic past (Gu et al., 2011) is not supported by the time-dependent and time-invariant simulations shown in Fig. 16c. The simulation without changes in temperature or POC begins to accumulate hydrate with 50 million years of the simulation (dashed line, Fig. 16c). The time-varying simulation, subjected to warmer temperatures but higher POC rain during the middle of the simulation (Fig. 4), does not produce hydrate until the warm, high-POC time is finished at around 150 million years (Fig. 16c, solid line).

The hydrate inventory in the model responds to methane sources other than biological degradation of POC. A model sensitivity run with thermogenic methane production disabled (called No Thermogen), and the simulation No Petroleum, which disables secondary respiration of migrating petroleum, each produce about $60 \%$ of the hydrate from the comparable low-resolution base case.

However, the hydrate inventory is so responsive to reasonable changes in primary POC respiration that were we to neglect these processes in the model, the rate of primary respiration could be increased enough within the uncertainties to bring the hydrate inventory up to much higher values (e.g. the Labile $100 \%$ simulation). Therefore, these results do not constitute a hard prediction of the relative contributions of these processes to the hydrates in real margin sediments, but rather a statement of the relative sensitivities of the hydrate inventory, which is much higher to changes in biological respiration of POC than to petroleum or thermogenic methane.

\subsection{Sensitivity to bubble transport}

The hydrate inventory in the model depends critically on methane transport by rising bubbles through the sediment column, and re-dissolution if the bubbles enter an undersaturated condition. This mechanism is novel to SpongeBOB, not shared by the Davie and Buffett (2001) or most other 1-D methane hydrate accumulation models. If bubble transport is disabled, hydrate nearly disappears from the results (Fig. 16, simulation No Bubb Mig). Figure 17e shows the 
extreme model sensitivity to the re-dissolution height scale, which determines what fraction of the methane will be recaptured by re-dissolution rather than escape directly to the sea floor. When a scale height of $2 \mathrm{~km}$ is imposed, hydrate nearly disappears from the simulation. Shortening the height scale from $500 \mathrm{~m}$ to $100 \mathrm{~m}$ increases the hydrate inventory by a more than a factor of four. Clearly this is a parameter to which the model is very sensitive, and further work will be required to capture the complexities of the real world in a numerical model.

\subsection{Pore fluid flow heterogeneity}

Old iodine-129 ages in pore waters at Blake Ridge, relative to the age of the solids, can only be reproduced in the model as resulting from heterogeneity in the pore fluid flow field, as crudely mimicked in the code by the vertical high-permeability channels. This conclusion is reinforced by the heterogeneity in penetration depth for dissolved sulfate, $\mathrm{SO}_{4}^{2-}$ (Borowski et al., 1996), which seem to show a bimodal distribution, with some sites where the methane/sulfate boundary is just a few tens of meters, and others where sulfate reaches hundreds of meters or more. The shallow sites correlate with the presence of methane hydrate, just like in the model where the hydrate is found. The importance of the channels justifies the imposition of an upward flow in the Davie and Buffett one-dimensional model (2001), which was interpreted as representing a zone of upward flow, analogous to the channels here.

However, the impact of the channels on the hydrate inventory itself is relatively small in the model and not apparently robust, in that the high resolution model saw an increase in hydrates when the channels were disabled, but the lower resolution simulations showed no difference. Disabling the horizontal anisotrophy in sediment permeability along with the permeable channels (No Anisotrophy) also had a minor impact.

\subsection{Other model sensitivities}

The Low Slope scenario produces significantly more hydrate than the base case, probably because of the expanded seafloor area within the hydrate-bearing zone on the broader slope of that simulation. Eliminating landslides (No Slides), which allowed a somewhat steeper slope but did not change the hypsometry very much, did not change the hydrate inventory relative to the base case.

The No SO4 scenario increased the hydrate inventory by about $70 \%$, by steering respiration toward methanogenesis rather than sulfate reduction, and eliminating anaerobic oxidation of methane as a methane sink availability of dissolved sulfate in the ocean as an upper boundary condition to the model.

Most of the other scenarios had a fairly minor impact on the hydrate inventory, when viewed within the context of the limitations of the coarse numerical grid. Examples include clay dewatering and dissolved organic carbon production and degradation.

\section{Conclusions}

The SpongeBOB model treats the coastal margin methane cycle from a much larger perspective than previous models of methane hydrate accumulation in margin sediments. The model domain spans to bedrock, closing the budgets for pore fluid and carbon, and into the onshore-offshore dimension. When heterogeneities in the sediment permeability are introduced, the lateral dimension becomes an integral part of the dynamics, rather than the model being a sort of palisade of one-dimensional systems. Also, rates of sedimentation are governed by the evolution of the water depth overlying the sediment column, so that sedimentation variations in time are controlled by things going on in the lateral dimension. Its two-dimensional formulation therefore allows the model to span geologic time.

Bubble migration through the sediment column is an important part of the methane cycle in the model. Viewed from a basin perspective, it is no surprise that methane is lost from the deep sediment column. Another related but separate question is how much of the methane gas lost from the deep sediment column is recaptured to the dissolved phase.

The SpongeBOB model departs from most previous models of methane hydrate accumulation (Burdige, 2011; Chatterjee et al., 2011; Davie and Buffett, 2001; Davie and Buffett, 2003a; Davie and Buffett, 2003b; Garg et al., 2008; He et al., 2011; Liu and Flemings, 2007; Xu, 2004) by postulating that this upward bubble flux might play a role in the stratigraphic methane hydrate deposits on passive continental margins. It turns out that the model methane hydrate inventory depends very strongly on the scale height for methane re-dissolution within an undersaturated zone. The fate of methane gas within the sediment column clearly needs further attention and development.

Heterogeneity in the vertical flow field, simulated very crudely in SpongeBOB as vertical channels of increased permeability, affect chemical tracers such as iodine-129 and $\mathrm{SO}_{4}^{2-}$, as well as focusing the formation of methane hydrate in the channels. Old $\mathrm{I}^{129}$ ages in hydrate-bearing sediments (Fehn et al., 2000) and the observed correlation between $\mathrm{SO}_{4}^{2-}$ penetration depth and presence of hydrate (Borowski et al., 1996) are consistent with the conclusion that hydrate distribution is steered by upward flow.

The abundance of methane hydrate in the model is poised on a knife's edge, responding very strongly to changes in the degradation rate of organic matter, to gas transport and redissolution in the sediment column, and to ocean and subsurface temperatures. For this reason it is currently impossible to calculate the global inventory of methane hydrate from modeling first principles. The goal of the process-oriented model 
SpongeBOB is to weigh the relative sensitivities of the hydrate inventory to potential changes in forcings in the past and future, and to identify processes that need to be understood better in the real world, such as gas transport.

\section{Supplementary material related to this article is available online at: http://www.biogeosciences.net/9/ 2859/2012/bg-9-2859-2012-supplement.zip.}

Acknowledgements. This paper benefited from the comments of the editor Jack Middelberg and reviewers Jerry Dickens and another anonymous reviewer. The modeling project was funded by DOE NETL project DE-NT0006558. Plots were done using Ferret, a product of NOAA's Pacific Marine Environmental Laboratory (http://ferret.pmel.noaa.gov/Ferret/).

Edited by: J. Middelburg

\section{References}

Archer, D. E., Morford, J. L., and Emerson, S. R.: A model of suboxic sedimentary diagenesis suitable for automatic tuning and gridded global domains, Global Biogeochem. Cy., 16, 17 pp., doi:10.1029/2000GB001288, 2002.

Athy, L. F.: Density, porosity and compaction of sedimentary rocks, AAPG Bull., 14, 1-24, 1930.

Bear, J.: Dynamics of fluids in porous media, Elsevier, New York, 764 pp., 1972.

Bianchi, T. S.: The role of terrestrially derived organic carbon in the coastal ocean: A changing paradigm and the priming effect, Proc. Nat. Aca. Sci. USA, 108, 19473-19481, 2011.

Borowski, W. S.: A review of methane and gas hydrates in the dynamic, stratified system of the Blake Ridge region, offshore southeastern North America, Chem. Geol., 205, 311-346, 2004.

Borowski, W. S., Paull, C. K., and Ussler, W.: Marine pore-water sulfate profiles indicate in situ methane flux from underlying gas hydrate, Geology, 24, 655-658, 1996.

Boudreau, B. P., Algar, C., Johnson, B. D., Croudace, I., Reed, A., Furukawa, Y., Dorgan, K. M., Jumars, P. A., Grader, A. S., and Gardiner, B. S.: Bubble growth and rise in soft sediments, Geology, 33, 517-520, 2005.

Buffett, B. and Archer, D. E.: Global inventory of methane clathrate: Sensitivity to changes in environmental conditions, Earth Planet. Sci. Lett., 227, 185-199, 2004.

Burdige, D. and Geiskes, J. M.: A pore water/solid phase diagenetic model for manganese in marine sediments, Am. J. Sci., 283, 2947, 1983.

Burdige, D. J.: Temperature dependence of organic matter remineralization in deeply-buried marine sediments, Earth Planet. Sci. Lett., 311, 396-410, 2011.

Chatterjee, S., Dickens, G. R., Bhatnagar, G., Chapman, W. G., Dugan, B., Snyder, G. T., and Hirasaki, G. J.: Pore water sulfate, alkalinity, and carbon isotope profiles in shallow sediment above marine gas hydrate systems: A numerical modeling perspective, J. Geophys. Res.-Sol. Earth, 116, B09103, doi:10.1029/2011JB008290, 2011.
Daigle, H. and Dugan, B.: Permeability anisotropy and fabric development: A mechanistic explanation, Water Resour. Res., 47, L20301, doi:10.1029/2010GL044970, 2011.

Davie, M. K. and Buffett, B. A.: A numerical model for the formation of gas hydrate below the seafloor, J. Geophysical Res., 106, 497-514, 2001.

Davie, M. K. and Buffett, B. A.: Sources of methane for marine gas hydrate: inferences from a comparison of observations and numerical models, Earth Planet. Sci. Lett., 206, 51-63, $2003 \mathrm{a}$.

Davie, M. K. and Buffett, B. A.: A steady state model for marine hydrate formation: Constraints on methane supply from pore water sulfate profiles, J. Geophys. Res., B10, 2495, doi:10.1029/2002JB002300, 2003b.

Fehn, U., Snyder, G., and Egeberg, P. K.: Dating of pore waters with I-129: Relevance for the origin of marine gas hydrates, Science, 289, 2332-2335, 2000.

Flemings, B. P., Liu, X., and Winters, W. J.: Critical pressure and multiphase flow in Blake Ridge gas hydrates, Geology, 31, 10571060, 2003.

Flemings, P. B., Stump, B. B., Finkbeiner, T., and Zoback, M.: Flow focusing in overpressured sandstones: Theory, observations, and applications, Am. J. Sci., 302, 827-855, 2002.

Garg, S. K., Pritchett, J. W., Katoh, A., Baba, K., and Fujii, T.: A mathematical model for the formation and dissociation of methane hydrates in the marine environment, J. Geophys. Res.Sol. Earth, 113, B01201, doi:10.1029/2006JB004768, 2008.

Gu, G., Dickens, G. R., Bhatnagar, G., Colwell, F. S., Hirasaki, G. J., and Chapman, A. G.: Abundant Early Palaeogene marine gas hydrates despite warm deep-ocean temperatures, Nat. Geosci., 4, 848-851, 2011.

Haq, B. U., Hardenbol, P. R., and Vail, P. R.: Chronology of fluctuation sea levels since the Triassic, Science, 235, 1156-1167, 1987.

He, L.-J., Lei, X.-L., and Zhang, Y.: Numerical modeling of gas hydrate accumulation in the marine sediments of Shenhu Area, Northern South China Sea, Chinese J. Geophys., 54, 128501292, 2011.

Hedges, J. I. and Keil, R. G.: Sedimentary organic matter preservation an assessment and speculative synthesis, Mar. Chem., 49, 81-115, 1995.

Hill, J. C., Driscoll, N. W., Weissel, J. K., and Goff, J. A.: Large-scale elongated gas blowouts along the US Atlantic margin, J. Geophys. Res.-Sol. Earth, 109, B09101, doi:10.1029/2004JB002969, 2004.

Hunt, J. M.: Petroleum Geochemistry and Geology, Freeman, New York, 743 pp., 1995.

Hunt, J. M., Philp, R. P., and Kvenvolden, K. A.: Early developments in petroleum geochemistry, Organic Geochem., 33, 1025 1052, 2002.

Iamori, H., McKenzie, D., and Tahakashi, E.: Melt generation by isentropic mantle upwelling, Earth Planet. Sci. Lett., 134, 253266, 1995.

Jain, A. K. and Juanes, R.: Preferential Mode of gas invasion in sediments: Grain-scale mechanistic model of coupled multiphase fluid flow and sediment mechanics, J. Geophys. Res.-Sol. Earth, 114, B08101, doi:10.1029/2008JB006002, 2009.

Jain, A. K., Kheshgi, H. S., Hoffert, M. I., and Wuebbles, D. J.: Distribution of radiocarbon as a test of global carbon cycle models, Global Biogeochem. Сy., 9, 153-166, 1995. 
Jorgensen, B. B.: Comparison of Methods for the Quantification of Bacterial Sulfate Reduction in Coastal Marine-Sediments, 2. Calculation from Mathematical-Models, Geomicrobiol. J., 1, 2947, 1978.

Kennett, J. P.: Marine Geology, Prentice-Hall, Englewood Cliffs, NJ, 1982.

Leas, W. J., Jenks, L. H., and Russell, C. D.: Relative permeability to gas, Trans. Am. Inst. Min. Eng., 189, 65-72, 1950.

Liu, X., and Flemings, P. B.: Dynamic multiphase flow model of hydrate formation in marine sediments, J. Geophys. Res.-Sol. Earth, 112, B03101, doi:10.1029/2005JB004227, 2007.

Maier-Reimer, E., Hasselman, K., Olbers, D., and Willebrand, J.: An ocean circulation model for climate studies, Hamburg, Germany, 1982.

Mayer, L.: Mineral associations and nutritional quality of organic matter in shelf, Deep-Sea Res., 49, 4587-4597, 2002.

Meiburg, E. and Kneller, B.: Turbidity currents and their deposits, Ann. Rev. Fluid Mech., 42, 135-156, 2010.

Middelburg, J. J.: A simple rate model for organic matter decomposition in marine sediments, Geochim. Cosmochim. Acta, 53, 1577-1582, 1989.

Parson, B. and Sclater, J. B.: An analysis of the variations in ocean floor bathymetry and heat flow with age, J. Geophys. Res., 82, 803-827, 1977.

Pirmez, C., Pratson, L. F., and Steckler, M. S.: Clinoform development by advection-diffusion of suspended sediment: Modeling and comparison to natural systems, J. Geophys. Res.-Sol. Earth, 103, 24141-24157, 1998.

Reagan, M. T. and Moridis, G. J.: Oceanic gas hydrate instability and dissociation under climate change scenarios, Geophys. Res. Lett., 34, L22709, doi:10.1029/2007GL031671, 2007.

Rodger, P. M.: Methane hydrate - Melting and memory, in: Gas Hydrates: Challenges for the Future, 474-482, 2000.

Rodgiruez, N. M., Paull, C. K., and Borowski, W. S.: 30. Zonation of authigenic carbonates with gas hydrate-bearing sedimentary section on the Blake Ridge: Offshore Southeastern North America, in: Proceedings of the Ocean Drilling Program, Scientific Results, edited by: Paull, C. K., Matsumoto, R., and Wallace, D. W. R., 301-312, 2000.
Sivan, O., Shrag, D. P., and Murray, R. W.: Rates of methanogenesis and methanotrophy in deep-sea sediments, Geobiology, 5, 141151, 2007.

Strobel, J., Cannon, R., Kendall, C. G. S., Biswas, G., and Bezdek, J.: Interactive (Sedpak) Simulation of Clastic and Carbonate Sediments in Shelf to Basin Settings, Comput. Geosci., 15, 12791290, 1989.

Syvitski, J. P. M.: 2D SEDFLUX 1.0C: an advanced processresponse numerical model for the, Comput. Geosci., 27, 731753, 2001.

Treguer, P., Nelson, D. M., Bennekom, A. J. v., DeMaster, D. J., Leynaert, A., and Queguiner, B.: The silica balance in the world ocean: A reestimate, Science, 268, 375-379, 1995.

Wallmann, K., Aloisi, G., Haeckel, M., Obzhirov, A., Pavlova, G., and Tishchencko, P.: Kinetics of organic matter degradation, microbial methane generation and gas hydrate formation in anoxic marine sediments, Geochim. Cosmochim. Acta, 70, 3905-3927, 2006.

Wallmann, K., Aloisi, G., Haeckel, M., Tishchenko, P., Pavlova, G., Greinert, J., Kutterolf, S., and Eisenhauer, A.: Silicate weathering in anoxic marine sediments, Geochim. Cosmochim. Acta, 72, 2895-2918, 2008.

Watts, A. B.: Isostasy and flexure of the lithosphere, Cambridge University Press, Cambridge, UK, 2001.

Whiticar, M. J. and Faber, E.: Methane Oxidation in Sediment and Water Column Environments - Isotope Evidence, Organic Geochem., 10, 759-768, 1986.

$\mathrm{Xu}, \mathrm{W}$. Y.: Modeling dynamic marine gas hydrate systems, Am. Mineral., 89, 1271-1279, 2004.

Yang, X.-S.: Theoretical Basin Modeling, Exposure Publishing, 212 pp., 2006. 